
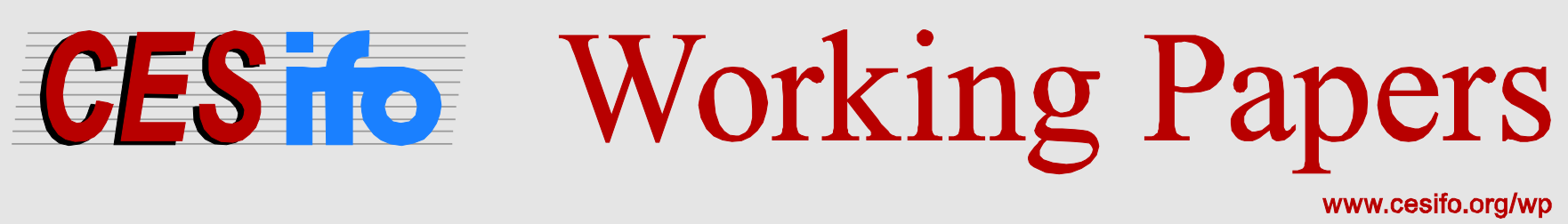

\title{
A Model to Evaluate Vehicle Emission Incentive Policies in Japan
}

\author{
Don Fullerton \\ Li Gan \\ Miwa Hattori
}

\author{
CESIFO WORKING PAPER NO. 4866 \\ CATEGORY 9: RESOURCE AND ENVIRONMENT ECONOMICS \\ JUNE 2014
}

An electronic version of the paper may be downloaded

- from the SSRN website:

- from the RePEc website:

- from the CESifo website:

wWw.SSRN.com

www.RePEc.org

www.CESifo-group.org/wp 


\title{
A Model to Evaluate Vehicle Emission Incentive Policies in Japan
}

\begin{abstract}
Using three years of data from the 47 prefectures of Japan, we estimate behavior of households who simultaneously make discrete decisions about vehicle ownership and continuous decisions about driving distance. We use the estimated parameters to calculate elasticities and to simulate the effects of alternative pollution control policies such as taxes on gasoline, on distance, or on particular cars. Given choices about cars and distance, we also calculate emissions. Since we model simultaneous choices, both the chosen distance and the chosen car can be affected either by a tax on distance or by a tax on car characteristics. We find expected signs for coefficients on price and income. Car choices are relatively inelastic, however, either to taxes on cars or to taxes on gas or distance. Thus emissions are more affected by taxes on gasoline than by taxes on particular vehicles. Yet taxes on cars have lower costs on consumers and thus lower marginal cost of abatement. Given that the existing gas tax already achieves some abatement, mostly through driving reduction, this analysis suggests that further abatement from the use of distance-reducing taxes is more costly than achieving some marginal abatement from induced changes in car choices. The option with the lowest cost is to tax each car at a rate proportional to its emission rate.
\end{abstract}

JEL-Code: Q480.

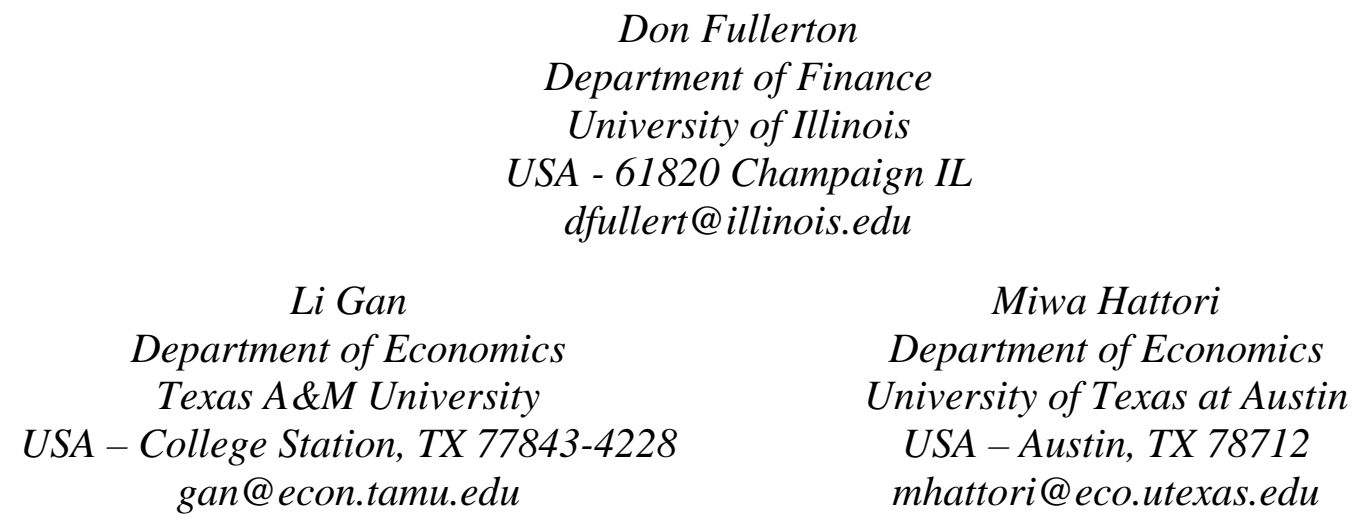

We are grateful for financial support from Japan's Economic and Social Research Institute (ESRI), for logistical support from PM-Keypoint, and for comments from Toshi Arimura, Frank Convery, Hilary Sigman, Karl Storchman, and Sarah West. All remaining errors belong to us. 
Accumulation of carbon dioxide $\left(\mathrm{CO}_{2}\right)$ and other greenhouse gases may lead to significant future costs of global warming and other climate changes. Burning of fossil fuel also emits regional pollutants such as sulfur dioxide $\left(\mathrm{SO}_{2}\right)$ and local pollutants such as carbon monoxide (CO), nitrous oxides $\left(\mathrm{NO}_{\mathrm{x}}\right)$, and hydrocarbons $(\mathrm{HC})$ that react with sunlight to cause health-damaging urban ozone $\left(\mathrm{O}_{3}\right)$. The control of these emissions may be a complex issue in light of various national interests, problems with data, analytical issues, difficulties of international coordination, and high uncertainty.

Vehicles are a significant source of these pollutants. According to International Energy Agency (2013, page 71), the transport sector in 2011 contributed $31.0 \%$ of $\mathrm{CO}_{2}$ emissions in the United States and $18.5 \%$ in Japan. Upon the adoption of the Kyoto Protocol, Japan agreed to cut emissions to the same level as in 1995. According to International Energy Agency (2013, page 50), the 2011 emissions of $\mathrm{CO}_{2}$ in Japan were only $1.8 \%$ higher than that of 1995.

According to Pigou (1920), the costs of reducing emissions can be minimized by the use of incentives such as a pollution tax or permit system. A price per unit of emissions provides all the right incentives to reduce emissions by using all the cheapest avenues of abatement: switch to cleaner fuels, employ abatement technology, or reduce the usage of energy itself.

This theory works well for stationary sources such as electric power plants, where the technology is available to measure emissions in a reliable and cost-effective manner. Some empirical studies have found that initial market incentive policies for electric power plants in the United States have significantly reduced the costs of $\mathrm{SO}_{2}$ emission abatement (Schmalensee et al, 1998). However, the theory cannot be applied so easily to mobile sources where the measurement technology is simply not available. ${ }^{1}$

This paper investigates alternative policies such as taxes on gasoline or on cars that could help achieve efficient methods of vehicle emission abatement in Japan. What are the effects of each such policy on car choices and driving behavior, and what are the effects of those driving behaviors on emissions? To answer these questions, we use three years of data for the 47 prefectures of Japan to estimate the simultaneous determination of household discrete choice of vehicle and continuous demand for

\footnotetext{
${ }^{1}$ On-board monitoring devices are imperfect and costly (Harrington and McConnell, 2003). Remote sensing is less expensive, but cannot measure emissions precisely for every car (Sierra Research, 1994).
} 
driving distance. We then use those estimates to simulate policies, to predict new behaviors, and to calculate emissions. We also find the equivalent variation measure of welfare cost, and we use it to plot the marginal cost of abatement (MCA).

If a vehicle emissions tax were feasible, then drivers could buy a newer, cleaner car, buy a smaller car with better fuel efficiency, fix their pollution control equipment, buy cleaner gas, or drive fewer kilometers. Moreover, an emissions tax would induce consumers with different incomes or characteristics to choose different combinations of these abatement methods, as required for economic efficiency. Some with old cars may speed up plans to switch to a newer or smaller car, while others with easier access to public transit may switch to no car. Still others may pay the tax instead of changing their habit. As an alternative to such incentives, command-and-control regulations tend to ignore heterogeneity, requiring the same forms of abatement for all drivers.

While the inability to measure emissions may preclude a per-unit tax on vehicle emissions, it does not preclude any use of incentives. Price mechanisms can still apply to any observable choice, especially to market transactions that generate an invoice for verification where the auto dealer or gas station can collect the tax or provide a subsidy. Heterogeneity is respected, allowing each individual to choose the vehicle and distance. In fact, incentive instruments have been at the center of discussion about environmental policies in Japan. ${ }^{2}$ The Japanese government charges annual registration fees that can be made to depend on vehicle characteristics, and periodic inspections can record odometers for a tax on distance.

A few papers have previously explored market incentives that could be used in place of a unit tax on vehicle emissions. ${ }^{3}$ Several other papers have estimated models of discrete choice among vehicle types. ${ }^{4}$ Some estimate the demand for gasoline or for distance traveled as functions of relevant prices and incomes, and some others have

\footnotetext{
${ }^{2}$ See e.g. Ministry of the Environment of Japan (1998), at http://www.env.go.jp/en/rep/tax/ishitax.pdf .

${ }^{3}$ For examples, see Eskeland and Devarajan (1996), Innes (1996), Kohn (1996), Plaut (1998), Sevigny (1998), and Fullerton and West (2002, 2010). For a review article, see Parry et al (2007). Fullerton and West (2010) simulate the effects of incentive policies with heterogeneous households, but they do not model discrete choices. Their parameters for the simulations are calibrated rather than estimated. In a theoretical model of discrete choices, De Borger (2001) derives optimal combinations of fixed taxes on vehicles and variable tax on distance.

${ }^{4}$ For U.S. examples, see McFadden (1979), Train (1986), Brownstone et al (1996), Brownstone and Train (1999), and other papers reviewed in McFadden (2001). For Japan, see Hibiki and Arimura (2005).
} 
predicted emissions. ${ }^{5}$ Several papers have used the sequential method of Dubin and McFadden (1984) to estimate both discrete choice of vehicle and continuous choice of distance (e.g. Mannering and Winston, 1985, Goldberg, 1998, and West, 2004). This sequential method first estimates the discrete vehicle choice, which generates estimates of parameters in the indirect utility function. The predicted choice of vehicle is then used to correct for endogeneity in estimating the implied demand for distance. This second step generates another set of estimates of the same parameters, but it does not constrain the estimates from the second step to match the estimates of the first step. Finally, a few new papers are introducing simultaneous methods to obtain a single set of estimates of these parameters. ${ }^{6}$

Relative to this literature, our paper makes several contributions. First of all, the Dubin-McFadden procedure was designed for individual household data, such as data available for the United States employed by all studies listed in text or footnotes above. In contrast, data for other countries may only be aggregated. In our case, the Japanese government would not release the micro data. Hibiki and Arimura (2005) also have no individual household data. In developing countries, adequate micro data may not even exist. Here, we develop a procedure to use aggregate data for the 47 prefectures of Japan, a procedure that requires modification to the basic framework of Dubin and McFadden. Second, we do this while estimating discrete and continuous choices simultaneously. Thus, the price of gasoline can affect both gas demand and car choices, while a car's price also affects gas demands and discrete choices. Our method generates one set of consistent estimates. Third, we allow for unobserved heterogeneity, which is important because different prefectures may react to the same price change in different ways. Not only does vehicle choice affect distance, but the agent-specific

\footnotetext{
${ }^{5}$ See the review in Harrington and McConnell (2003). For an example of emissions models, the U.S. EPA (1998, pp.3-68) discusses the MOBILE5a model and the California's EMFAC7F model.

${ }^{6}$ A simultaneous method is proposed by Hanemann (1984), but his method does not consider unobserved individual heterogeneity - a key factor in the Dubin-McFadden model. Bhat (2005) allows consumers to choose multiple discrete alternatives, while Bhat et al (2009) use this approach to analyze the effects of gasoline price on the choice of vehicle type, vintage, and use. Bento et al (2009) estimate car choices and miles driven with one set of parameters; they combine those demands with a model of new and used car supplies to simulate efficiency and distributional effects of an increase in the gasoline tax. These papers estimate discrete and continuous demands in one step with one set of parameters, but without the same individual error term in both choices. This unobserved individual heterogeneity is a key factor in the Dubin-McFadden model. Feng et al (2013) introduce a method of simultaneous estimation that captures the individual unobserved heterogeneity.
} 
error in our continuous demand estimation can also affect the choice of vehicle. We integrate over this error to produce the estimates and to calculate elasticities. Fourth, we also integrate over this error to simulate policy changes such as adding to the existing tax on gasoline or adding a tax on distance driven or on cars (such as a tax proportional to the car's emission rate). ${ }^{7}$ Fifth, for each policy, we calculate resulting emissions and welfare effects. Using demands derived from utility maximization allows us to solve back for the change in utility and the equivalent variation.

Our results suggest that the gasoline price per kilometer has an effect on choices of some cars more than others, and effects on distance driven more in some cars than in others. Car costs have small effects both on car choices and distance driven (and thus on emissions). However, those "small effects" are not enough to conclude that a tax by car type is ineffective. Though a tax on the car's age or its emission rate has small effects on emissions, it also has small costs on consumers. Either car tax has a marginal cost per unit of abatement (MCA) that is smaller than taxes on gasoline or distance.

Section I develops the multinomial logit model used to estimate both the discrete choice of vehicle and the continuous demands for driving. Section II describes the data, while Section III presents estimation results and elasticities. Section IV discusses how seven alternative environmental policies may reduce emissions, and it simulates these policies using the estimated parameter values. Section V concludes.

\section{Model}

Our basic framework derives from the model of Dubin and McFadden (1984), where they conduct the estimation in two steps: first they apply a logit model to estimate the discrete choice, and then conditional on that choice, they estimate a continuous demand. Compared with the Dubin-McFadden model, our framework has two distinguishing characteristics. First, since we do not have micro-level data showing individual choices, we have to deal with aggregate data for each of the 47 prefectures in Japan. Second, we build a model to estimate simultaneously the discrete choice of vehicles and continuous demand for distance.

\footnotetext{
${ }^{7}$ These simulations represent market outcomes only if supply curves are horizontal. Calculations for a change in the price of a new car or old car can be interpreted as a new local tax or subsidy in a small open jurisdiction that can import more of those new or old cars at a constant price. However, our demand system could be combined with some other estimates of supply to calculate equilibrium outcomes.
} 
Assume that a total of $K$ types of vehicles are available from which individual households can choose. In our empirical work below, we consider $K=5$ to include four vehicle types and the no-car option. For a household making choice $i$, direct utility is a function of vehicles kilometers traveled (VKT) and another consumption good $c$, that is, $U=U\left(V K T_{i}, c_{i}\right)$. Given income $y$, the budget constraint is:

$$
\frac{p_{g}}{K P L_{i}} V K T_{i}+c_{i}=y-\rho k_{i},
$$

where $p_{g}$ is the price of gasoline (in yens per liter), and $K P L_{i}$ is fuel efficiency of car type $i$ (in kilometers per liter), so that $p_{i} \equiv p_{g} / K P L_{i}$ is the price in yens per kilometer. The price of the other consumption good is normalized to 1 . The vehicle's annual rental cost is assumed to take the form $\rho k_{i}$, where $k_{i}$ is the total capital value of choice $i$ (depreciated or market value), and $\rho$ is the annual rental rate (which includes interest cost and further depreciation). We assume that $\rho=0.25$ (but we also try other values and find almost no difference in results below). ${ }^{8}$ The indirect utility from choice $i$ is a function of household income and prices, and it is denoted as $V\left(y-\rho k_{i}, p_{i}\right)$.

One common way to obtain the indirect utility function is to use a parametric $V K T$ demand equation and then solve a partial differential equation from Roy's identity (Hausman, 1981). For comparability with other studies, we use a log-linear specification for each VKT equation:

$$
\ln \left(V K T_{i}\right)=\alpha_{0}+\alpha_{1 i} p_{i}-\beta\left(y-\rho k_{i}\right)+x^{\prime} \gamma+\eta
$$

where $x$ is a vector of other observed socio-demographic variables that may affect $V K T$. The index on $\alpha_{1 i}$ means that an increase in the price of gasoline (and thus $p_{i}$ ) could affect desired distance in some cars more than in others. If it discourages driving in large cars and households can substitute, it could even increase distances in small fuel-efficient cars. The random error $\eta$ represents agent-specific unobserved factors that may affect both the vehicle choice and VKT. It is assumed that $\mathrm{E}(\eta)=0$.

As pointed out by Dubin and McFadden (1984), however, the conditional expectation $\mathrm{E}(\eta \mid$ bundle $i)$ is not zero, as can be seen clearly if we rewrite (2) as:

\footnotetext{
${ }^{8}$ The $25 \%$ rental rate is consistent with a $5 \%$ annual interest cost plus a $20 \%$ depreciation rate (which we use later to calculate the current value of each car, $k_{i}$ ).
} 


$$
\ln \left(V K T_{i}\right)=\alpha_{0}+\sum_{j} \alpha_{1 j} p_{j} d_{i j}-\beta \sum_{j}\left(y-\rho k_{j}\right) d_{i j}+x^{\prime} \gamma+\eta
$$

where $d_{i j}$ is a choice indicator variable equal to one when $i=j$. The random error $\eta$ is correlated with $d_{i j}$. Taking the expectation of (3), we have:

$$
\ln \left(V K T_{i}\right)=\alpha_{0}+\sum_{j} \alpha_{1 j} p_{j} S_{j}^{*}-\beta \sum_{j}\left(y-\rho k_{j}\right) S_{j}^{*}+x^{\prime} \gamma,
$$

where $S_{j}^{*}$ is a predicted probability that the $j$ th bundle is chosen. Equation (4) is called the "Reduced Form Method" in Dubin and McFadden (1984). They obtain $S_{j}^{*}$ from a first-stage logit model, while we obtain it simultaneously.

Using Roy’s identity and equation (2), the implied indirect utility function is:

$$
V_{i}=\frac{1}{\beta} \exp \left(-\alpha_{0 i}+\beta\left(y-\rho k_{i}\right)-x^{\prime} \gamma-\eta\right)-\frac{1}{\alpha_{1 i}} \exp \left(\alpha_{1 i} p_{i}\right)
$$

We assume that the individual chooses vehicle type $i$ that yields the highest indirect utility $V_{i}$. Observed vehicle choices then can be used to estimate the parameters of (5). However, note that the parameters of the vehicle choice in (5) are the same parameters as in the distance choice in (4). ${ }^{9}$ Indeed, for many households, the choice of vehicle and desired distance are interrelated. For this reason, we use (4) and (5) together to estimate parameters that best characterize simultaneous choices by consumers regarding vehicles and distance. Now the index on $\alpha_{1 i}$ means not just that an increase the price of gasoline (and thus $p_{i}$ ) can differentially affect distances in each type of car, but that it can have different effects on the choice of car. A higher gas price can decrease demand for large cars and increase demand for small, fuel-efficient cars.

Next, as in the usual discrete choice model, we add a choice-specific error term $\varepsilon_{i}$ to equation (5) that represents the difference between the true individual utility at choice $i$ and the calculated utility level. In practice, this error term for each choice $i$, conditional on agent-specific error term $\eta$, is assumed to be independently distributed over choices with an extreme value distribution. Using this extreme value distribution, we integrate over $\eta$ to obtain an expression for $S_{i n}^{*}$, the expected probability of

\footnotetext{
${ }^{9}$ An exception is that utility in (5) allows for constant terms $\alpha_{0 i}$ that depend on choice $i$, to reflect unobserved differences that affect utility but are not captured by $p, y$, or $x$. These constants also differ from $\alpha_{0}$ in equation (4), to capture scale differences between utility and $\ln (V K T)$. As described below, the vehicle bundles include a no-car option, and we normalize the indirect utility from this bundle to zero.
} 
choosing bundle $i$ at prefecture $n$. Dubin and McFadden (1984) have individual household data with actual choices, so they use a logit model to estimate predicted probabilities (the shares $S_{i n}^{*}$ ). In our case, aggregate prefecture data provide observed shares $\left(S_{i n}\right)$. We add an error term $u_{\text {in }}$ to reflect the difference between these, so that $S_{i n}=S_{i n}^{*}+u_{i n}$. We then estimate simultaneously the following moment conditions: ${ }^{10}$

$$
\begin{aligned}
& S_{i n}=\int_{\eta} \frac{\exp \left(V_{i n}(\eta)\right)}{\sum_{j}^{K} \exp \left(V_{j n}(\eta)\right)+1} f(\eta) d \eta+u_{i n} \\
& \ln \left(V K T_{i n}\right)=\alpha_{0}+\sum_{j} \alpha_{1 j} p_{j n} S_{j n}^{*}-\beta \sum_{j}\left(y_{n}-\rho k_{j n}\right) S_{j n}^{*}+x_{n}^{\prime} \gamma+v_{i n}
\end{aligned}
$$

In (6b), we have added an error term $v_{i n}$ to represent the difference between observed and predicted kilometers traveled. Both $u_{i n}$ and $v_{i n}$ are assumed to be independent across different choices and across different prefectures. We estimate (6) using Generalized Method of Moments (GMM), as described more below.

Once we obtain the parameter estimates, we are ready to calculate elasticities for both discrete choices and continuous demand. Let $z_{i}$ denote either $k_{i}$ or $p_{i}$. Then, the own-price and cross-price elasticities for the discrete choice model are given by:

$$
\begin{array}{ll}
\text { Own-price elasticity: } & \frac{\partial S_{i}}{\partial z_{i}} \frac{z_{i}}{S_{i}}=\frac{\partial V_{i}}{\partial z_{i}} z_{i}\left(1-S_{i}\right), \\
\text { Cross-price elasticity: } & \frac{\partial S_{i}}{\partial z_{j}} \frac{z_{j}}{S_{i}}=-\frac{\partial V_{j}}{\partial z_{j}} z_{j} S_{j} .
\end{array}
$$

Note that the right-hand-side of (7b) does not depend on $i$, so variable $z_{j}$ has the same cross-price effect on share $i$ for all choices $i \neq j$. For example, a change in the distance price $p_{j}$ has the same cross-price effect on all of the other four vehicle choices. The elasticity of choice $i$ with respect to income is given by:

$$
\frac{\partial S_{i}}{\partial y} \frac{y}{S_{i}}=y\left(\frac{\partial V_{i}}{\partial y}-\sum_{j} S_{j} \frac{\partial V_{j}}{\partial y}\right)
$$

For continuous distance demands, the formula for the own-price elasticity is:

\footnotetext{
${ }^{10}$ Dubin and McFadden (1984) use simplifying assumptions that make $\eta$ drop out of (6a). Here, we integrate over $\eta$, so our model is a mixed logit model as discussed in McFadden and Train (2000).
} 


$$
e_{p_{i}}=\frac{\partial \ln \left(V K T_{i}\right)}{\partial \ln p_{i}}=\alpha_{1 i} p_{i}
$$

We can also calculate the income elasticity $e_{y}$ and capital cost elasticity $e_{k i}$, as:

$$
e_{y}=\frac{\partial \ln (V K T)}{\partial \ln y}=-\beta y, \quad e_{k i}=\frac{\partial \ln (V K T)}{\partial \ln k}=\beta \rho k_{i} .
$$

In equations (7) - (10), each elasticity is typically evaluated at the mean values of $y$ and $k_{i}$ and at the average price per kilometer for each choice.

\section{Data}

\section{A. General Data Description}

To analyze behavior of households choosing automobile bundles and VKT, we could use household-level micro-data on each household's characteristics, income and expenditures, vehicle ownership, kilometers driven, and each vehicle's characteristics including fuel efficiency in kilometers per liter $(K P L)$, local emissions per kilometer $(E P K)$, and carbon dioxide emissions per kilometer (CPK). To our knowledge, no single data set that is publicly available contains all such information for Japan. ${ }^{11}$

The Family Income and Expenditure Survey (FIES) conducted by the Ministry of Public Management, Home Affairs, Posts and Telecommunications of Japan provides some data on income, expenditures on gasoline, car purchases, and other private transport-related costs, as well as the price of gasoline and the purchase price of cars (but it contains no distinction among car attributes). ${ }^{12}$ The micro-data with household characteristics and spending are not disclosed to any party outside the nation of Japan, however, so we must use the publicly available aggregate data found in "The Annual Reports on the Family Income and Expenditure Survey,” published by the Statistics Bureau of Japan. Since the aggregate data are available for each prefecture, we treat the 47 Japanese prefectures as units of observation, for each of the three years 2000-2002. That is, each observation describes the average household in a particular prefecture in a particular year, so we think of each prefecture as a single household in the sample. We pool the data for three years to obtain a sample size of $47 \times 3=141$ observations.

\footnotetext{
${ }^{11}$ Automakers may collect some of this information, and others may collect data using surveys, but these data are neither complete nor readily accessible.

${ }^{12}$ See http://www.stat.go.jp/english/data/kakei/1560.htm for an outline of the FIES.
} 


\section{B. Classification of Vehicle Bundles}

In our model, an agent representing an individual household faces a discrete choice among a finite number of vehicle bundles. Each bundle is identified by the vehicle's type according to size and vintage. In particular, we define our vehicle types according to the engine size measured in liters of total displacement, as is customary in the Japanese classification of passenger cars. The regular passenger car class (denoted by subscript $r$ ) consists of cars with total displacements of 2.0 liters and above, while the small passenger car class (denoted by s) consists of cars with total displacement less than 2.0 liters. ${ }^{13}$ The vehicle vintages are classified by new cars (denoted by $n$ ) versus old cars (denoted $o$ ). Vehicle bundles are then described by a set of subscripts $\{r n, r o, s n, s o, 0\}$, where 0 denotes the zero-vehicle bundle.

\section{The Data Sources}

(1) Household income and expenditures on gasoline. We use the FIES data to obtain the prefectural average of expenditure on gasoline and total expenditures (which we use as total income). The FIES data for a given year are collected through a survey of randomly selected households throughout all of Japan. The selection of households is based on a three-stage stratified sampling method, where the sampling units at the three stages are the municipality, the survey unit area, and the household. The capital city of each prefecture is a stratum, and some reported data series contain only households in the capital city rather than the entire prefecture, but we must in any case assume that all households of a given prefecture behave similarly. Some statistics reported in the Annual Reports are based on surveys among Workers’ Households, and some others are based on All Households. We use the Annual Report for 2000, 2001, and 2002, supplemented by some series taken from the Report for 1999.

(2) Household characteristics. Since demographic characteristics are not in the Annual Reports of FIES, even at the prefecture level, we use the 2000 Population Census - the most recent census conducted in Japan. These data are entirely public, and

\footnotetext{
${ }^{13}$ Japan has another class, light vehicle, consisting of passenger cars with total displacement less than 0.660 liters. This class is dropped from our study because it does not exist in the U.S., and so no data are available for its emissions. The next section describes our U.S. sources for emissions data. Of passenger cars in Japan, light vehicles were $20 \%$ in 2002, and rising. Our multinomial logit model has the property of "independence of irrelevant alternatives", so parameter estimates are not affected by this omission. Thus, the calculated marginal effects and elasticities are unaffected. Average effects across all vehicles are likely over-estimated, however, because light vehicles presumably have lower mean effects.
} 
can be obtained freely from http://www.stat.go.jp/english/data/kokusei/index.htm. For each prefecture, we obtain from the Census the average family size, fraction of residents with higher-education, fraction of households residing in densely inhabited districts (“metro”), fraction of residents under 15 years of age (“child”), average number of income earners per household (“earner”), the fraction of households with two earners, the average age of household heads, and the homeowner fraction of households. Table 1 shows summary statistics for our demographic variables.

(3) Household-owned vehicle characteristics. Unfortunately, we cannot observe detailed characteristics of household-owned vehicles such as make, model, year, vehicle vintage, and number of cylinders. Since the prefecture is our unit of observation, we need at least the fraction of households owning each car bundle in each prefecture (including the choice of no vehicle). The Automobile Statistics Data Books published yearly by the Japan Automobile Dealers Association (JADA, 2000, 2001, 2002) shows registered vehicles by type and by prefecture. It also quantifies new car purchases of each type in each prefecture. ${ }^{14}$ To divide owned cars into two age categories, we use a two-year period for new car purchases. Thus, for each size category in each prefecture, the number of new cars (vintage type $n$ ) in 2000 is the number purchased new in 1999 and 2000. Subtracting this quantity from the number of registered vehicles of that size in the year 2000, we obtain the quantity of old cars (vintage type o). Vehicle quantities for 2001 and 2002 are obtained similarly. Because these statistics from the JADA Data Books are only for the households who own at least one automobile, we supplement them by the reported percentage of households owning no vehicle. ${ }^{15}$

(4) Fuel efficiency of vehicles. To our knowledge, no source in Japan provides data on fuel efficiency and emission rates (except for brand new cars). Since we need test results for older cars, we use data on cars in the U.S. to approximate fuel efficiency and emissions of cars in Japan. Technologies are similar in the two countries, and cars made in Japan are sold in the U.S., suggesting that a sample of Japanese cars found in the U.S. would be a good proxy for cars available to Japanese consumers.

\footnotetext{
14 The quantity of new cars purchased is not reported in the Data Books, but JADA personnel testify that the reported number of first-time registrations of new cars represents this quantity.

${ }^{15}$ For this purpose, we use a report on the passenger vehicle market by Japan Automobile Manufacturers Association (JAMA, http://www.jama.or.jp/release/news/prev/2000/03/000329_t1.html). These figures, however, are not available by prefecture.
} 
We use the results of recent vehicle testing by the California Air Resources Board (CARB, 1997, 2000) in the Unites States to estimate KPL for each size-vintage bundle. The dataset consists of two sub-samples: first, in "series 13", the CARB tested a total of 345 passenger cars, light-duty trucks, and medium-duty vans from November 1995 to March 1997; and second, in "series 14", the CARB sampled 332 vehicles from November 1997 to August 1999. Each observation in the CARB data represents an individual tested car and contains the manufacturer, year, and model, along with fuel efficiency (measured in miles per gallon, $M P G$ ). We then identify and extract the subset of tested cars that are made by Japanese manufacturers (Toyota, Nissan, Mazda, Mitsubishi, Honda, Isuzu, and Subaru). The extracted subset is a sample of 234 Japanese vehicles. We then divide this subset into our two engine size categories, which leaves us with 96 regular-size cars and 138 small-size cars. For each set, we estimate $M P G$ as a function of vehicle age (in years) using a semi-log specification. ${ }^{16}$ The estimation results are shown in the first panel of Table 2.

For both types of cars, results confirm that fuel efficiency declines with age. We can evaluate the estimated regression at any particular age to get predicted MPG. For new cars of each size, we assume age $=1$. For old cars, we use the reported mean of age of each type of passenger car in Japan for each year. ${ }^{17}$ Averaging over all three years, estimated fuel efficiencies are: $M P G_{r n}=21.9, M P G_{r o}=21.1, M P G_{s n}=29.0$, and $M P G_{s o}=27.5$. We multiply these figures by 0.4251 to convert to $K P L$, listed in Table 3 .

(5) Emissions of local pollutants. The critical data on emissions per kilometer $(E P K)$ of individual cars tested in Japan are unavailable. ${ }^{18}$ The CARB data provide test results on the emissions rates per mile (EPM) of carbon monoxide (CO), nitrous oxides $\left(\mathrm{NO}_{\mathrm{x}}\right.$ ), and hydrocarbons (HC's) for each tested vehicle. Moreover, we can calculate the weighted sum of these emissions, using weights from Fullerton and West (2010):

\footnotetext{
${ }^{16}$ Even if a given car has the same $M P G$ in Japan as in the U.S., however, the mix of regular-size cars (over 2.0 liters) in the U.S. may differ from the mix of such cars in Japan. Thus the MPG of regular cars in Japan could differ from the MPG predicted from this regression on Japanese cars in the U.S.

${ }^{17}$ These data are provided by the Automobile Inspection and Registration Association (AIRA) of Japan (http://www.aira.or.jp/data/ pdf/ age.pdf). For years 2000, 2001, and 2002, respectively, the average age for regular-size cars is 4.8, 5.2, and 5.6 years; for small-size cars the average age is $6.3,6.5$, and 6.6 years.

${ }^{18}$ For brand new cars, tests are performed by Japanese manufacturers to meet the established emission standards and to release their models' environmental specifications. For older vehicles, however, no emissions test is done in Japan that is equivalent to that by the CARB. Japan Automobile Research Institute (JARI), a public-service and test-research organization, has handled a few cases of emissions testing on used cars. Unfortunately, the data from those cases cannot be disclosed.
} 


$$
E P M=0.1 \times C O+0.495 \times N O_{x}+0.405 \times H C .
$$

Using the sample of 234 Japanese cars described in the previous subsection, we estimate a semi-log equation for EPM of each car size as a function of vehicle age. ${ }^{19}$ The second panel in Table 2 reports the estimation results. Then, to obtain the emission rate for each new vehicle bundle, we evaluate the estimated emission rate regression at $a g e=1$. For each old bundle, we use the reported means of the age of passenger cars in Japan for each year 2000 through 2002. For each bundle, Table 3 shows the calculated emissions per kilometer ( $E P K)$, averaging over those three years. These vary from 0.216 for a new regular-size vehicle to 0.549 for an old small-size vehicle. Surprisingly, for either age category, the larger cars have lower emission rates than the smaller cars. ${ }^{20}$

(6) Carbon dioxide emissions. While the data on $\mathrm{CO}_{2}$ emissions per kilometer $(C P K)$ of individual cars tested in Japan are unavailable, the aforementioned "series 14" of the CARB data provides test results on the carbon dioxide emission rate per mile (CPM). We extract and obtain a sample consisting of 117 cars made by Japanese manufacturers. We then divide it into our two engine size categories, yielding 48 regular cars and 69 small cars. For each set, we estimate $\ln (C P M)$ as a function of vehicle age (in years). The results shown in the last panel of Table 2 reveal that the carbon emission rate does not depend much on age, but it does depend on size. When we use those estimates to calculate carbon dioxide per kilometer ( $C P K)$, Table 3 shows that the mean for regular cars is about 250 and for small cars is about 190 (grams/km).

(7) Market value of vehicles. Although the Annual Reports on the FIES offer the prefectural averages of purchase prices of all cars (with no distinction by the cars' attributes), we need a market value for each of the four vehicle bundles (for capital cost,

\footnotetext{
${ }^{19}$ A problem is that emission rate standards differ between Japan, California, and the rest of the US, but we do not use these emissions data in estimation of the behavioral model of household choice. Instead, after the behavioral model is estimated, we simulate tax policies, calculate changes in car choices and distance demand, and then use these emission rates only to calculate the implied effect on emissions. These calculations of emissions are the best we can do, given data limitations, but are still "illustrative".

${ }^{20}$ Fullerton and West (2010) regress emission rate on engine size (in cubic inches of displacement) and find the coefficient is positive and significant at the $10 \%$ level. When we use our US sample with all cars, $E P M$ is a U-shaped function of size. Four cylinder cars have less EPM than eight cylinder cars, but more EPM than six cylinder cars. The "small" car in Japan corresponds roughly to four cylinders in the US data, and regular cars correspond roughly to six cylinders, so small cars have higher emissions.
} 
$\left.k_{i}\right) .{ }^{21}$ For new cars, we can use the manufacturers' suggested retail prices of selected models available on multiple Japanese manufacturers' websites. Using the list of the ten most popular models published in the JADA Data Book per year, we obtain each $k_{r n}$ and $k_{s n}$ as the weighted average of the retail prices of the subset of models belonging to each size class, with the weight being the share of each model. We assume that cars depreciate at a rate of $20 \%$ per year, so used car prices $k_{r o}$ and $k_{s o}$ are calculated as:

$$
k_{r o}=k_{r n} \times 0.8^{a a r} \text {, and } k_{s o}=k_{s n} \times 0.8^{a a s} \text {, }
$$

where aar is the average age of regular cars, and aas is the average age of small cars in each year. That year's market value for any vehicle bundle is thus obtained, but it does not vary across prefectures. Table 3 lists this market value of each bundle.

(8) Gasoline price per kilometer. As described above, the FIES provides each year's average price of gasoline for each prefecture (in yens per liter). These are observed gasoline prices and include the existing gasoline tax (uniform across Japan). The bottom of Table 1 shows the mean gasoline price across prefectures, as well as mean gasoline expenditure and total expenditure. For each vehicle bundle, we then combine each year's prefectural data on gasoline price $p_{g}$ (in yens per liter) and each year's fuel efficiency $K P L_{i}$ (in kilometers per liter) to calculate the price of distance $p_{\text {in }}$ (in yens per kilometer). Here, we assume that gasoline expenditures are the only cost per kilometer. ${ }^{22}$ For each vehicle bundle, the bottom of Table 3 shows the mean and standard deviation of this price per kilometer, over 47 prefectures.

(9) Vehicle kilometers traveled (VKT). Since VKT is not observed directly, we use data on $E_{n}$, the average household's expenditure on gasoline in prefecture $n$. We take $E_{n}$ (in yens per household) and divide by $p_{\text {in }}$ (in yens per kilometer) to get $V K T$ (in kilometers per household). Thus, the dependent variable on the left side of (6b) becomes $\left[\ln \left(E_{n}\right)-\ln \left(p_{\text {in }}\right)\right]$.

\section{Estimation Results}

\footnotetext{
${ }^{21}$ Other fixed costs may include insurance, finance charges, and license fees. Following West (2004), we assume that market value serves as a good proxy because these other costs vary closely with market value. However, Toshi Arimura points out that the cost of renting a parking space differs across prefectures.

${ }^{22}$ Some maintenance cost may generally add to this cost, but we have no clear way to divide maintenance cost into the part that is required regardless of kilometers and the part that should be treated as a cost per kilometer. West (2004) adds tire cost per kilometer to the calculation of per-kilometer costs. Expenditures on tires, unfortunately, are not reported for Japanese households.
} 
We have information on each prefecture's shares $\left\{S_{r n}, S_{r o}, S_{s n}, S_{s o}, S_{0}\right\}$, but the sum of these five shares is one. To avoid the problem of collinearity, we use only the first four shares to form four moment conditions based on (6a). Since $p_{\text {in }}$ vary across the four vehicle types, we have four additional moment conditions that are based on continuous demand for VKT in (6b). We employ GMM to estimate our model on these eight moment conditions. Estimating (6a) requires some distribution of the random error $\eta$, so we assume $\eta$ to be distributed as standard normal. The estimation results are reported in Table 4.

In Table 4, the first five parameters are the key parameters in our paper, and all five are significantly different from zero. The coefficients on per-kilometer gas prices $\left\{\alpha_{1 i}\right\}$ are all negative and highly significant. Thus, for each car choice, people drive less when they face a higher cost per kilometer. Next, note that the demand for VKT in equation (6b) includes total expenditure (income) with a negative sign in front of it. The estimated coefficient on this income variable $(\beta)$ is negative, so people drive more when they have more income (net of the capital cost of their vehicle). Table 4 also indicates that distance demand is greater for households that own their own homes, are younger, have more children, and live outside a metropolitan area. Note that these interpretations are tricky, however, because these parameters serve dual roles: they determine distance choices and discrete car choices.

Our primary interest is to understand how people respond to changes in the gas price per kilometer, total expenditure (income), and capital cost. To analyze these questions, we calculate elasticities using the formulas derived above, for both discrete choice and continuous demand. Table 5 lists own-price and cross-price elasticities for the discrete choices with respect to gas price per kilometer. Table 6 lists all own-price and cross-price elasticities for the discrete choices with respect to each capital cost $\left(k_{i}\right)$ and the elasticity of each choice with respect to income $(y)$. Finally, Table 7 shows all continuous VKT demand elasticities. ${ }^{23}$

In Table 5, for the gasoline price in any row, the table shows the effect on each vehicle bundle choice, that is, the change in the probability of choosing that column's

${ }^{23}$ All discrete and continuous elasticities are derived from the single set of estimates in Table 4 obtained from our simultaneous method. Feng et al (2013) estimate both sequential and simultaneous versions of the same basic model, in order to compare results. We do not make such comparisons here, but instead choose to proceed into new ground: policy simulations, welfare changes, and MCA calculations. 
car for a one percent change in gas cost per kilometer in that row. The diagonal shows own-price elasticities. As expected, the own-price elasticity for each choice is negative, while the cross-price elasticities are positive for all car types. In other words, an increase in one car's driving cost would decrease the market share of that same car but increase market shares of other cars. Given a car size (regular or small), the own-price elasticity of the new car choice is much smaller than that of the old car (in absolute value). That is, household choice to own an old car is more negatively affected by the gas price than is the choice to own a new car. For example, a 1\% increase in the gas price of choice $s n$ induces a $0.69 \%$ decrease in the probability of choosing sn, while the same change to the gas price of choice so induces a $2.7 \%$ decrease in the probability of that choice. Note that a gas price change for choice $r n$ barely alters any market share.

The first part of Table 6 presents capital cost elasticities for the discrete choice model. Each elasticity gives the percentage change in market share of the column car associated with a one-percent increase in the capital cost of the row car. As expected, all own-price elasticities are negative while cross-price elasticities are positive for all car types. Thus an increase in the capital cost of a car would decrease the probability of owning that same car, and increase the probabilities of owning each other car (or no car). Quantitatively, however, all entries are close to zero; any change in capital cost barely affects the market share of any choice. The last row of Table 6 reports the share elasticities with respect to income (total expenditure). The last entry for the no-car option is negative, suggesting that an increase of income makes households less likely to hold no car, as expected. The other entries have different signs; more income increases the share of small old cars and decreases other shares. ${ }^{24}$

Table 7 shows effects of key variables on VKT, given each car choice. Goldberg (1998) calls these short-run elasticities, because the household can change its distance but not its car. The short-run elasticity of $V K T$ with respect to gas price per kilometer is negative for every choice. The VKT elasticity for small old cars is -0.555 , in the

\footnotetext{
${ }^{24}$ West (2004) does not report discrete car choice elasticities with respect to gas price, car price, or income. Goldberg (1998) reports large elasticities. In any case, their results are not comparable for several reasons: they use US data, they use sequential estimation, and the bundles are defined differently.
} 
range of previous estimates. ${ }^{25}$ However, elasticities for the other three car types are substantially higher (-2.4 to -11.2). Perhaps these estimates are "too high" and unreliable because we estimate a structural model and because we are limited to data for prefectures rather than for individual households. Yet perhaps other prior results are "too low" and unreliable because they do not capture the simultaneity of car and distance choices by households, as we do here. We still have no "final” results, but we believe that results here are important indicators that we need further investigation.

In any case, relative elasticities are instructive. Given car size, for example, Table 7 shows that VKT demand is more responsive to a change in gas price for new cars than for old cars. For regular cars in the first two rows, the VKT elasticity is -2.378 if old and -11.23 if new. For small cars in the next two rows, the elasticity is -0.555 if old and -2.383 if new. For a different comparison, taking vintage as given, VKT demand is substantially more responsive to the gas price for regular-sized cars than for small cars. If old, this elasticity is -0.555 for small cars and -2.378 for regular cars. If new, it is -2.383 for small cars and -11.23 for regular cars. An explanation can be found in Table 3, where a regular-sized car is shown to be less fuel efficient than a small car. If they are both the same vintage, a unit increase in the gas price of a regular car affects the distance driven more than does an increase in the gas price of a small car.

The form of our model in equation (5) and our negative estimated $\beta$ together imply that income has a positive effect on indirect utility - as expected. Thus, in Table 6, more income decreases the probability of owning no car. Also, as expected, a higher capital cost $k_{i}$ reduces the probability of owning car $i$. In our model of simultaneous discrete and continuous choices, however, equation (10) shows that VKT elasticities are $e_{y}=-\beta y$ and $e_{k i}=\beta \rho k_{i}$. Thus, the same estimated $\beta<0$ means that more income must raise VKT demand, and a higher capital cost must reduce VKT demand. As shown in Table 7 , a household drives $0.23 \%$ more when income rises by one percent. ${ }^{26}$ However, it reduces driving by less than $0.04 \%$ when any capital cost rises by one percent.

\section{Simulations of Various Environmental Policies}

\footnotetext{
${ }^{25}$ In general, using US data, the distance elasticity with respect to gas price is estimated to be about -0.2 by Goldberg (1998) and -0.9 by West (2004). It is only around -0.03 from either the sequential or simultaneous procedure of Feng et al (2013).

${ }^{26}$ Using US data, the distance elasticity with respect to income is found to be insignificant in Goldberg (1998), 0.02 in West (2004), and around 1.0 in Feng et al (2013).
} 
Our estimates already incorporate current policies, because the data on gasoline prices reflect existing taxes, and the purchase prices of vehicles include the acquisition taxes currently levied by the Japanese government. ${ }^{27}$ We now use the estimated parameters to perform a number of simulations to compare the effects of alternative reforms. For any particular policy, we can use the characteristics of the Japanese population along with the estimated parameters to predict the proportion of households that hold each vehicle, the total distance driven, and total emissions. The benchmark for comparison is the status quo. For the current policy regime, the simulated household average VKT is 4,029 kilometers per year. The average household has local emissions of 1.914 kilograms and $\mathrm{CO}_{2}$ emissions of 819 kilograms.

For each vehicle, note that $V K T$ in equation (4) and utility in (5) both depend on the price per unit distance $\left(p_{i}\right)$ and the cost of the vehicle $\left(k_{i}\right)$. Therefore, each policy needs to be translated into "model-equivalent form," that is, a change in either $p_{i}$ or $k_{i}$. In this paper, we focus on one policy at a time rather than combinations of policies.

\section{A. Policies that Alter the Price per Kilometer}

First, we consider policy options that affect $p_{i}$, including a tax per liter of gasoline $\left(t_{g}\right)$, a tax per unit distance $\left(t_{d}\right)$, or even the possibility of a tax per unit of local pollutant emissions $\left(t_{e}\right)$ or carbon emissions $\left(t_{c}\right)$. To incorporate any such policy, the new general form for the price per kilometer for choice $i$ is:

$$
p_{i}^{\prime}=\left[\frac{p_{g}+t_{g}}{K P L_{i}}+t_{e} E P K_{i}+t_{c} C P K_{i}+t_{d}\right]
$$

For these purposes, the existing gasoline tax is embodied in $p_{g}$, so any tax rate in (12) represents an added tax. We next describe our simulations.

1.) A tax per unit of local emissions $\left(t_{e}>0, t_{c}=t_{g}=t_{d}=0\right)$. An emissions tax in yens per gram times $E P K_{i}$ in grams per kilometer yields the effect on the price in yens per kilometer. As discussed above, this policy is not available if emissions are too difficult or costly to measure. Emissions are not a market transaction with an invoice to verify the tax base for collection and enforcement. However, the concept of taxing each

\footnotetext{
${ }^{27}$ The current acquisition tax on a passenger vehicle is $5 \%$ of “acquisition price”, regardless of whether the car is new or used. The "acquisition price" of a vehicle for purposes of this tax is determined by the retail price of the model when sold brand new and the age of the particular vehicle.
} 
unit of emissions has been shown to minimize the total social cost of achieving any given emissions-abatement target, and it thus represents an important ideal against which to compare all other realistic policy options. We assume that consumers know how their vehicle choices affect emissions, and thus tax due, so this policy may induce households to choose cleaner-burning cars as well as to drive less.

2.) A tax per unit of $\mathrm{CO}_{2}$ emissions $\left(t_{c}>0, t_{e}=t_{g}=t_{d}=0\right)$. This policy may be more feasible than the tax on local pollutants, because it can be imposed on the carbon content of each fuel when purchased. While local emissions depend on characteristics of the vehicle, carbon emissions are closely related to the carbon content of fuels.

3.) A tax per liter of gasoline $\left(t_{g}>0, t_{c}=t_{e}=t_{d}=0\right)$. This policy is technically feasible and enforceable, as the Japanese government currently collects such a tax. ${ }^{28}$

4.) A tax per kilometer driven $\left(t_{d}>0, t_{c}=t_{g}=t_{e}=0\right)$. The car's driving distance is not purchased in a market transaction, but kilometers driven are more observable than emissions. Old style odometers might be rolled back by consumers who want to cheat, but new cars have electronic odometers that are more difficult to change. If each car is inspected once a year, even just for the usual safety inspection, the inspector can record the distance, and the prefecture can include the calculated tax in the annual registration fee. In theory, the distance tax ought to perform better than a gas tax, because it avoids the "rebound effect" discussed in Harrington and McConnell (2003). A gas tax might induce consumers to buy more fuel-efficient cars, so the higher $K P L_{i}$ partly offsets the higher price per kilometer, but $t_{d}$ cannot be avoided in any way except by reducing driving distance. However, the distance-tax would not reduce emissions as much as $t_{e}$, because $t_{e}$ encourages other abatement methods that affect $E P K_{i}$.

For all of these tax rates, we infer a reasonable range from the current gasoline tax rate in Japan, 53.8 yens per liter. To implement an added tax that is $5 \%$ to $100 \%$ of the existing gas tax, we choose the range of $t_{g}=2.69$ to 53.8 (¥/liter), as shown in the second row of Table 8 . We then we find how much on average (across vehicle choices) each gas tax rate adds to the per-kilometer price of driving ( $\Delta p$ in the first row). We use that $\Delta p$ to calculate the comparable range for $t_{e}, t_{c}$, and $t_{d}$ (shown in rows 3 to 5).

\footnotetext{
${ }^{28}$ Both the national government and prefectures levy taxes on gasoline. The current rates are 48.6 yens/liter at the national level and 5.2 yens/liter at the prefecture level.
} 
For any tax, we use equation (12) to get the new price per kilometer for each vehicle, and we use those in conjunction with the estimated parameters to calculate the new choices of vehicle types, distances traveled, and the resulting total emissions. Figures 1-3 show simulated effects on $V K T$, local emissions, and $\mathrm{CO}_{2}$ emissions.

Figure 1 shows effects on VKT of the four taxes when they are scaled to raise the per-kilometer cost by the same amount on average. A tax on local emissions (in yens/gram) reduces vehicle distances the most, followed by the distance tax (per $\mathrm{km}$ ), the gasoline tax (per liter), and the $\mathrm{CO}_{2}$ tax (per gram). The solid dark line shows that doubling the existing gas tax will achieve about $40 \%$ reduction in $V K T$, whereas a tax of 14 yens per gram of local pollutants would raise the price per kilometer the same amount (Table 8) and reduce driving distances by 55\% (Figure 1).

Figure 2 shows the control of local emissions achieved by these comparable rates of tax on gasoline, distance, and emissions. The points where each curve crosses the horizontal line labeled “-30” indicate that government can cut local pollutants by about $30 \%$ of the status-quo level by charging an extra 2.3 yen per km through $t_{e}$, or an extra 3.3 yen per km through $t_{d}$. To bring about the same $30 \%$ reduction in emissions using the gasoline tax as the only instrument would require an extra 3.6 yen per km (an increase of almost $70 \%$ in the existing gas tax). Similarly, Figure 3 shows the degree of carbon dioxide abatement achieved by these taxes, when they are scaled to increase perkilometer costs by the same amount.

Figure 4 shows effects of an emissions tax on all five vehicle ownership shares. Figures 5-7 show analogous effects of the carbon tax, gas tax, and distance tax. In all four figures (for all four taxes), households shift away from using a small, old car (type so). This car has the largest emission rate, as seen in Table 3. All other choice shares rise. The choice that rises the least in all four figures is the one with the next highest emission rate (type ro, which also has the lowest fuel efficiency in Table 3). Thus, all four taxes tend to encourage newer cars. The local emissions tax in Figure 4 and carbon tax in Figure 5 raise the ro share only slightly, whereas the gasoline tax in Figure 6 and the distance tax in Figure 7 raise the ro share almost as much as the other shares. These latter two taxes encourage the no-car option almost as much as the sn option.

\section{B. Policies That Alter the Cost of Each Vehicle}


We now consider potential policy instruments to alter the capital cost or rental cost of some car types. Examples of such policies are taxes levied at the time of vehicle purchase (acquisition taxes), annual registration fees, or annual vehicle tax. The annual fixed cost for owning choice $i$ is now raised by $t_{i}$, the bundle-specific addition to the rental cost, in 100,000 yens, for $i=\{r n, r o, s n, s o\}$. We can then compare our simulation results to the corresponding benchmark outcomes.

1.) A tax on the size of the engine $\left(t_{s}\right)$. The correlation between the size of the engine and the emissions rate is ambiguous. Surprisingly, the calculation of EPK using local pollutants from the CARB data reveals that small cars have a larger EPK than regular cars (see Table 3). Whether this results from the specific nature of the CARB data remains unclear. It is well established, however, that size increases emissions of $\mathrm{CO}_{2}$, as is also shown using the CARB data ( $C P K$ in Table 3).

Japanese prefectures already collect annual fees on vehicles that rise with total displacement of engines, and so further taxation of size can be implemented easily. ${ }^{29} \mathrm{~A}$ tax on engine size can be modeled by the addition of $t_{r n}>0$ and $t_{r o}>0$ to the rental cost of regular-sized vehicles, with no change in the cost of small vehicles. We choose the range from $t_{r n}=t_{r o}=0.051$ to 0.510 ( $¥ 5,100$ to $¥ 50,100$ per year), in order to simulate the effects of an additional tax that ranges from one to ten times the existing annual fees on regular-sized vehicles (those over 2.00 liters). Figure 8 illustrates the results.

Because carbon emissions are related to vehicle size, this size tax in Figure 8 reduces $\mathrm{CO}_{2}$ by larger percentages than it reduces VKT or local emissions (LE). None of these reductions is larger than $0.005 \%$, however. As noted above, we found very small elasticities with respect to capital costs, both for car choices (Table 6) and for distance demand (Table 7). Thus, the simulated car ownership tax has only tiny effects on vehicle and distance choices. We find that this tax on engine size is not an effective policy tool for reducing emissions of any pollutant.

2.) A tax on the emissions rate $\left(t_{E P K}\right)$. Since $E P K_{i}$ is a characteristic of the car, this tax can also be modeled via changes to the annual cost of each vehicle. It may perform better than the size tax, as local emissions are more closely related to vehicle

\footnotetext{
${ }^{29}$ For home-owned cars, the annual fees are $¥ 29500$ (1.0 liter or less), ¥34500 (1.001-1.5 liters), ¥39500 (1.501-2.0 liters), $¥ 45000$ (2.001-2.5 liters), ¥51000 (2.501-3.0 liters), ¥58000 (3.001-3.5 liters), ¥66500 (3.501-4.0 liters), $¥ 76500$ (4.001-4.5 liters), ¥88000 (4.501-6.0 liters), and ¥111000 (6.001 liters or more).
} 
emission rates than to vehicle size. On the other hand, $E P K_{i}$ is not as easily measured as engine size for the purposes of imposing the tax. To make $t_{E P K}$ proportional to our estimated emission rates in Table 3, we initially set $t_{r n}=0.216$ (¥21,600/year), $t_{r o}=$ $0.402, t_{s n}=0.288$ and $t_{s o}=0.549$. Then we simulate $10 \%$ to $100 \%$ increases in these rates. Figure 9 (a) shows that the initial rates induce almost $0.6 \%$ reduction of all continuous variables ( $\mathrm{LE}, \mathrm{CO}_{2}$, and VKT). Doubling those tax rates achieves $1.1 \%$ reductions. This kind of tax could lead to a percentage cut in emissions that exceeds the percentage cut in $V K T$, but only if it shifts households into cars with low emission rates. These taxes affect capital cost, which has been shown to have only small effects on car choices. Figure 9(b) shows how these taxes induce small changes in vehicle shares.

3.) A tax on vehicle age $\left(t_{\text {age }}\right)$. In our framework, $t_{\text {age }}$ could be modeled as a tax on old cars or a subsidy to buying a new car. Age is more observable than $E P K_{i}$, yet highly correlated with emissions, so this policy might be nearly as effective as $t_{E P K}$. A disadvantage may be that a tax or subsidy related to age does not provide incentive for maintenance to reduce the vehicle's emissions rate, as would a tax on EPK.

In 2002, the Japanese government began implementing a Green Tax structure that adds $10 \%$ to the annual vehicle taxes already imposed on gasoline-driven vehicles that have been registered since 1991. Vehicles of eleven years of age or older continue to be subject to this yearly penalty in Japan. This policy is modeled here by setting $t_{r n}=$ $t_{s n}=0$ and $t_{r o}>0, t_{s o}>0$. We start with additional old-car taxes that are $10 \%$ of existing rates $\left(t_{r o}=0.051\right.$ and $\left.t_{s o}=0.0345\right)$, and we test the sensitivity of results by raising those added rates up to $100 \%$ of existing taxes.

Figure 10(a) shows that this age tax has very similar effects on all continuous variables (local emissions, $\mathrm{CO}_{2}$, and VKT). With added taxes equal to $100 \%$ of existing taxes, these variables all fall by $0.35 \%$. Compared to the tax on size, this tax on age raises the rental cost per vehicle by the same or less, and yet it induces more emission abatement and VKT reduction. The reason is that a large proportion of households own old cars and thus are affected by the tax. Figure 10(b) shows that this age tax discourages old cars that are small (so), but not necessarily larger old cars (ro). It does provide for slightly larger increases in the no-car share and new car shares.

\section{The Marginal Cost of Abatement}


To compare the cost-effectiveness of different abatement methods, many studies estimate production or cost functions and plot for each technology the marginal cost of abatement (MCA). Efficiency requires that such technologies be undertaken to a point where all have the same MCA. When all curves are plotted on the same diagram, an efficient combination is where all curves have the same height. Similar analysis for vehicles might show the MCA for adding a type of equipment or for reducing distance.

In this paper, as in Fullerton and Gan (2005), we use a somewhat different view of cost-effectiveness that compares policies instead of technologies. A policy such as the gasoline tax, for example, might induce several changes in technologies (changes in car choices and distance choices). For each rate of tax, we calculate how the combined changes in technologies affect emissions. We can also calculate the cost to consumers, which in this case is a loss of consumer surplus rather than cost of equipment per se. To calculate the cost to consumers, we use the indirect utility function for each car choice. For each household (i.e. prefecture), we calculate the utility level at the old equilibrium and at the new taxed equilibrium. We then iterate numerically to find the equivalent variation ( $\mathrm{EV})$, the yen amount that could be given to each household at the old prices that would allow them to attain the new utility level. This amount is negative for a loss, so the "cost" stated as a positive amount is -EV. Government obtains some added tax revenue, $\Delta \mathrm{R}$, so the net social cost or "deadweight loss" of the tax is DWL = $-E V-\Delta R$. Comparing each tax rate to a slightly higher tax rate, we take the added DWL over the additional abatement as the marginal social cost of abatement (MCA). Since the DWL generally starts near zero and rises with the square of the tax rate, one might expect the MCA to start near zero and to rise at an increasing rate.

For each tax instrument, we increment the tax rate and calculate the average household's change in local emissions, EV, additional DWL, and marginal cost of abatement. We show all MCA curves in Figure 11, where all curves are increasing, as expected. Perhaps surprisingly, the MCA are quite low for car taxes ( $t_{\text {age }}$ and $t_{E P K}$ ). Indeed, theory suggests that the tax on emissions $\left(t_{e}\right)$ is the least cost way to reduce emissions. The explanation is that this theory must be modified in a second best model with other existing taxes. The existing gasoline tax in our model is 53.8yen/liter, which essentially doubles the price of gasoline. Thus, any additional gas tax starts with a high 
marginal DWL. In Figure 11, the marginal cost of raising this existing gas tax is $¥ 5,000$ for the first additional gram of abatement per household.

Moreover, the cost of the existing gas tax is the consumer surplus lost from reduced driving, and that cost is exacerbated by any tax that further affects distance such as the tax on distance $\left(t_{d}\right)$ or on emissions $\left(t_{e}\right.$ or $\left.t_{c}\right)$. All those taxes start with MCA of about $¥ 5,000 /$ gram and rise from there. Among those taxes, the emissions tax does have the lowest MCA. In contrast, however, the car taxes ( $t_{\text {age }}$ and $\left.t_{E P K}\right)$ do not exacerbate the pre-existing cost of reduced driving distance. If these car taxes induce any switch toward low-emission cars, then they can reduce emissions at very low initial marginal cost of abatement - despite having small behavioral response elasticities.

Given that the existing gas tax already achieves some abatement, mostly through $V K T$ reduction, this analysis suggests that further abatement from the use of distancereducing taxes is more costly than achieving some marginal abatement from induced changes in car choices. The option with the lowest cost is to tax each car at a rate proportional to its emission rate in grams per kilometer.

\section{Conclusions and Future Research}

This paper develops a model for simultaneous estimation of consumer behavior regarding discrete choice of vehicle and continuous choice of distance driven in Japan. We make unique use of prefectural average data on households, the 2000 Population Census, and vehicle ownership information in Japan, all combined with fuel efficiency and emission rates estimated from U.S. vehicle testing data. We estimate the equations of this model simultaneously using general method of moments, and we find expected signs of effects on vehicle and driving choices from changes to income, the annual cost of each vehicle type, and the cost per kilometer of driving. Then we simulate different policy alternatives and show how they change driving distance and emissions.

Our model provides several opportunities for future research. First, it could be used to calculate the welfare-maximizing rate for all of these policy instruments used in combination. This possibility provides a computational analog to the voluminous literature on "optimal tax rates”. Second, the standard errors from the estimation could be used to calculate the standard errors around the predicted outcomes (costs, emission levels, and optimal tax rates). Third, the model could be used to analyze distributional 
results, with households categorized on some meaningful basis (such as annual or lifetime incomes). The set of all household equivalent variations could be used to calculate changes in Gini coefficients or progressivity indices. The usual expectation is that most of these emission policies are regressive, a fact that has discouraged the use of incentive policies to deal with vehicle emissions problems.

In this case, however, the model could be used to analyze subsidies to reduce emissions. If those subsidies are accepted by households with low income, then they might have relatively low cost of abatement and favorable distributional effects. This kind of result can only be calculated in a model incorporating all of our features: heterogeneity among households in terms of incomes and other characteristics that affect discrete choice of vehicle and continuous choice of distance; estimation of parameters and standard errors; multiple tax and subsidy policies that affect the relative price of kilometers driven in each vehicle; technical information to calculate emissions from each car; and the ability to solve for household welfare effects.

\section{References}

Automobile Inspection and Registration Association of Japan (AIRA), http://www.aira.or.jp/data/ pdf/ age.pdf (2003).

Bento, Antonio, Lawrence Goulder, Mark Jacobsen and Roger Von-Haefen. “Efficiency and Distributional Impacts of Increased U.S. Gasoline Taxes,” American Economic Review 99:3 (June 2009), 667-99.

Bhat, Chandra R. "A Multiple Discrete-Continuous Extreme Value Model: Formulation and Application to Discretionary Time-Use Decisions," Transportation Research: Part B: Methodological 39:8 (2005), 679-707.

Bhat, Chandra R., Sudeshna Sen, and Naveen Eluru. "The Impact of Demographics, Built Environment Attributes, Vehicle Characteristics, and Gasoline Prices on Household Vehicle Holdings and Use," Transportation Research: Part B: Methodological 43:1 (January 2009), 1-18.

Brownstone, David and Kenneth Train, "Forecasting New Product Penetration with Flexible Substitution Patterns,” Journal of Econometrics 89 (1999), 109-29.

Brownstone, D., D.S. Bunch, T.F. Golob, and W. Ren, “A Vehicle Transactions Choice Model for Use in Forecasting Demand for Alternative-Fuel Vehicles,” Research in Transportation Economics 4 (1996), 87-129.

California Air Resources Board, Test Report of the Light-Duty Vehicle Surveillance Program, Series 13, Project Number 2S95C1 (September 1997).

California Air Resources Board, Report of the Results of the Vehicle Surveillance Program 14, Project Number 2S97C1 (March 2000). 
De Borger, Bruno, "Discrete Choice Models and Optimal Two-Part Tariffs in the Presence of Externalities: Optimal Taxation of Cars,” Regional Science and Urban Economics 31 (2001), 471-504.

Dubin, Jeffrey and Daniel McFadden, “An Econometric Analysis of Residential Electric Appliance Holdings and Consumption,” Econometrica 52:2 (March 1984).

Eskeland, Gunnar and Shantayanan Devarajan, Taxing Bads by Taxing Goods: Pollution Control with Presumptive Charges, Washington: World Bank (1996).

Feng, Ye, Don Fullerton, and Li Gan, "Vehicle Choices, Miles Driven, and Pollution Policies”, Journal of Regulatory Economics 44 (August 2013), 4-29.

Fullerton, Don, and Li Gan, “Cost-Effective Polices to Reduce Vehicle Emissions”, American Economic Review Papers \& Proceedings 95:2 (May 2005), 300-4.

Fullerton, Don and Sarah West, "Can Taxes on Cars and on Gasoline Mimic an Unavailable Tax on Emissions?,” Journal of Environmental Economics and Management 43 (January 2002), 135-57.

Fullerton, Don and Sarah West, "Tax and Subsidy Combinations for the Control of Car Pollution,” The B.E. Journal of Economic Analysis \& Policy (Advances) 10:1 Article 8 (2010).

Goldberg, Pinelopi, “The Regulation of Fuel Economy and the Demand for 'Light Trucks’,” Journal of Industrial Economics 46:1 (March 1998), 1-33.

Hanemann, W. Michael, “Discrete/Continuous Models of Consumer Demand,” Econometrica 52:3 (May 1984), 54-62.

Harrington, Winston and Virginia McConnell, "Motor Vehicles and the Environment," in H. Folmer and T. Tietenberg, eds., International Yearbook of Environmental and Resource Economics 2003/2004, Northampton MA: Edward Elgar (2003).

Hausman, Jerry A., “Exact Consumer’s Surplus and Deadweight Loss,” American Economic Review 71:4 (September 1981), 662-76.

Hibiki, Akira and Toshi Arimura, "An Empirical Study of the Effect of the Fuel Tax in Japan on Vehicle Selection and NOx Emission,” Department of Social Engineering Discussion Paper, Tokyo Institute of Technology, http://www.soc.titech.ac.jp/ library/discuss/index_e.html (2005).

Innes, Robert, "Regulating Automobile Pollution Under Certainty, Competition, and Imperfect Information,” Journal of Environmental Economics and Management 31 (September 1996), 219-39.

International Energy Agency (IEA), “CO $\mathrm{CO}_{2}$ Emissions from Fuel Combustion” (2013), http://www.iea.org/publications/freepublications/publication/name,43840,en.html

Japan Automobile Dealers Association (JADA), The Automobile Statistics Data Book (1999, 2000, 2001, 2002).

Kohn, Robert E., “An Additive Tax and Subsidy for Controlling Automobile Pollution,” Applied Economics Letters 3 (July 1996), 459-62.

Mannering, Fred and Winston, Clifford, “A Dynamic Empirical Analysis of Household Vehicle Ownership and Utilization,” Rand Journal of Economics 16:2 (Summer 1985), 215-36. 
McFadden, Daniel, “Quantitative Methods for Analyzing Travel Behavior of Individuals: Some Recent Developments,” in David Hensher and P. Stopher, eds., Behavioral Travel Modeling, London: Croom Heml (1979), 279-318.

McFadden, Daniel, “Disaggregate Behavioural Travel Demand's RUM Side: A 30-Year Retrospective,” in Hensher, ed., Travel Behavior Research: The Leading Edge. London: Pergamon (2001).

McFadden, Daniel and Kenneth Train, "Mixed MNL Models for Discrete Response," Journal of Applied Econometrics 15:5 (2000), 447-70.

Ministry of the Environment of Japan, Environment Agency, Report of the Study Group on Economic Instruments in Environmental Policies, http://www.env.go.jp/en/rep/tax/ishitax.pdf (1998).

Parry, Ian W. H., Margaret Walls and Winston Harrington. "Automobile Externalities and Policies,” Journal of Economic Literature 45 (June 2007), 374-400.

Plaut, Pnina, “The Comparison and Ranking of Policies for Abating Mobile-Source Emissions,” Transportation Research D 3 (July 1998), 193-205.

Pigou, Arthur C., The Economics of Welfare, London: MacMillan (1920).

Sevigny, Maureen, Taxing Automobile Emissions for Pollution Control, Cheltenham, UK and Northhampton, MA: Edward Elgar Publishing Ltd. (1998).

Schmalensee, R., Paul Joskow, A. Denny Ellerman, Juan Pablo Montero and Elizabeth M. Bailey, “An Interim Evaluation of Sulfur Dioxide Emissions Trading,” Journal of Economic Perspective 12:3 (Summer 1998).

Sierra Research, Analysis of the Effectiveness and Cost-Effectiveness of Remote Sensing Devices, Report SR94-05-05, prepared for the U.S. Environmental Protection Agency, Sacramento, CA: Sierra Research (1994).

Statistics Bureau of Japan, The Annual Report on the Family Income and Expenditure Survey, conducted by Ministry of Public Management, Home Affairs, Posts and Telecommunications of Japan (1999, 2000, 2001, 2002).

Statistics Bureau of Japan, The 2000 Population Census, Online documentation, http://www.stat.go.jp/english/data/kokusei/index.htm (2003).

Train, Kenneth, Qualitative Choice Analysis: Theory, Econometrics, and an Application to Automobile Demand, Cambridge, MA: The MIT Press (1986).

Train, Kenneth, Discrete Choice Methods with Simulation, Cambridge, UK: Cambridge University Press (2003).

U.S. Environmental Protection Agency, Technical Methods for Analyzing Pricing Measures to Reduce Transportation Emissions, Washington, DC (1998).

West, Sarah, "Distributional Effects of Alternative Vehicle Pollution Control Policies," Journal of Public Economics 88:3-4 (March, 2004), 735-57. 
Table 1: Definitions and Summary Statistics

\begin{tabular}{llcc}
\hline Variable Name & Definition & Mean & $\begin{array}{c}\text { Standard } \\
\text { Deviation }\end{array}$ \\
\hline Famsize & Average number of people in a household & 2.797 & 0.018 \\
Education $^{\mathrm{a}}$ & Fraction of residents with higher education & 0.231 & 0.005 \\
Metro & Fraction in densely inhabited districts & 0.504 & 0.016 \\
Child & Fraction of population under 15 years old & 0.147 & 0.001 \\
Earner & Number of income earners per household & 1.419 & 0.012 \\
Two-earn & Dual-income fraction of households & 0.346 & 0.005 \\
Age & Average age of the head of a household & 52.6 & 0.133 \\
Own-home & Homeowners fraction of households & 0.655 & 0.006 \\
Income, $y$ & Yearly total expenditure (in ¥ 100,000) & 37.57 & 0.275 \\
Gas expenditure & Yearly spending on gasoline (¥ 100,000) & 0.5139 & 0.013 \\
Gasoline price & Gasoline price (in ¥ per liter) & 101.09 & 0.267 \\
Households & Number of households in prefecture & $1,001,335$ & 87,586 \\
\hline
\end{tabular}

(a) "Education" is the number of residents with more than high school education divided by the number of residents with at least 6 years of education not currently in school.

Table 2: Estimation of Fuel Efficiency and Emission Rates

\begin{tabular}{llcccc}
\hline & $\begin{array}{c}\text { Dependent } \\
\text { Variable }\end{array}$ & Constant & Age & $\mathrm{R}^{2}$ & $\begin{array}{c}\text { Number } \\
\text { of obs. }\end{array}$ \\
\hline Fuel Efficiency & & & & & \\
Regular-size cars & $\ln (M P G)$ & 3.093 & -0.0083 & 0.083 & 96 \\
& & $(0.0293)$ & $(0.0029)$ & & \\
Small-size cars & $\ln (M P G)$ & $\begin{array}{c}3.382 \\
(0.0250)\end{array}$ & $\begin{array}{c}-0.0128 \\
(0.0021)\end{array}$ & 0.217 & 138 \\
\hline Emission Rates & & & & & \\
\hline
\end{tabular}




\begin{tabular}{llcccc}
\hline Regular-size cars & $\ln (E P M)$ & $\begin{array}{c}-1.2067 \\
(0.1259)\end{array}$ & $\begin{array}{c}0.1480 \\
(0.0122)\end{array}$ & 0.609 & 96 \\
& & -0.8850 & 0.1176 & 0.465 & 138 \\
Small-size cars & $\ln (E P M)$ & $(0.1300)$ & $(0.0108)$ & & \\
& & & & & \\
\hline Carbon Dioxide Emission Rates & 6.008 & -0.0006 & 0.001 & 48 \\
Regular-size cars & $\ln (C P M)$ & $(0.0413)$ & $(0.0122)$ & & \\
& & 5.672 & 0.0091 & 0.144 & 69 \\
Small-size cars & $\ln (C P M)$ & $(0.0357)$ & $(0.0027)$ & & \\
\hline
\end{tabular}

Notes: Standard errors are reported in parentheses. These regressions use U.S. data to estimate miles per gallon $(M P G)$, emissions per mile ( $E P M)$, and carbon dioxide emissions per mile $(C P M)$ for Japanese cars only. When applied to cars in Japan, these are converted to kilometers per liter $(K P L)$, emissions per $\mathrm{km}(E P K)$, and carbon dioxide emissions per $\mathrm{km}(C P K)$.

Table 3: Summary Statistics of the Choice-specific Variables

\begin{tabular}{lccccc}
\hline Choices & $r n$ & ro & $s n$ & so & Means \\
\hline Bundle $i$ proportion & 0.042 & 0.210 & 0.081 & 0.453 & 0.1965 \\
& $(0.000)$ & $(0.001)$ & $(0.002)$ & $(0.003)$ & \\
Fuel efficiency $\left(K P L_{i}\right)$ & 9.294 & 8.975 & 12.348 & 11.703 & 10.580 \\
Emission rate $\left(E P K_{i}\right)$ & 0.216 & 0.402 & 0.288 & 0.549 & 0.364 \\
$\mathrm{CO}_{2}$ emission rate $\left(C P K_{i}\right)$ & 252.43 & 251.79 & 182.30 & 191.64 & 219.54 \\
Market value $\left(k_{i}\right.$ in $\left.¥ 100,000\right)$ & 24.649 & 7.708 & 14.462 & 3.436 & 12.564 \\
Gasoline cost $\left(p_{i}\right.$ in $\left.¥ / \mathrm{km}\right)$ & 10.88 & 11.26 & 8.19 & 8.64 & 9.74 \\
& $(0.029)$ & $(0.029)$ & $(0.022)$ & $(0.022)$ & \\
\hline
\end{tabular}

Notes: Standard errors are reported in parentheses. $K P L$ is kilometers per liter. $E P K$ is emissions per kilometer $(\mathrm{km})$. CPK is carbon-dioxide per kilometer. 
Table 4: Simultaneous Estimation of Discrete Choice and Continuous Demand

\begin{tabular}{|c|c|c|}
\hline Variable & Coefficient & t-statistic \\
\hline Gas cost per kilometer of choice $r n\left(\alpha_{1 r n}\right)$ & -1.032 & -42.62 \\
\hline Gas cost per kilometer of choice ro $\left(\alpha_{1 \text { ro }}\right)$ & -0.211 & -65.78 \\
\hline Gas cost per kilometer of choice sn $\left(\alpha_{1 s n}\right)$ & -0.291 & -37.78 \\
\hline Gas cost per kilometer of choice so $\left(\alpha_{1 s o}\right)$ & -0.064 & -49.61 \\
\hline Net income $(\beta)$ & -0.0062 & -3.034 \\
\hline Constant for choice $r n\left(\alpha_{0 r n}\right)$ & 5.178 & 11.04 \\
\hline Constant for choice ro $\left(\alpha_{0 \text { ro }}\right)$ & 6.920 & 14.11 \\
\hline Constant for choice $s n\left(\alpha_{0 s n}\right)$ & 5.455 & 11.43 \\
\hline Constant for choice so $\left(\alpha_{0 \text { so }}\right)$ & 2.831 & 5.830 \\
\hline Constant for continuous choice $\left(\alpha_{0}\right)$ & 8.765 & 33.34 \\
\hline Famsize & -0.102 & -1.587 \\
\hline Education & -0.716 & -3.299 \\
\hline Metro & -0.274 & -3.716 \\
\hline Child & 3.383 & 4.343 \\
\hline Earner & 0.130 & 2.579 \\
\hline Two-earn & -1.005 & 3.742 \\
\hline Age & -0.014 & -4.504 \\
\hline Own-home & 1.404 & 6.761 \\
\hline Dummy for Tohoku & 0.028 & 1.318 \\
\hline Dummy for Kanto & -0.031 & -1.348 \\
\hline Dummy for Hokuriku & 0.050 & 1.795 \\
\hline Dummy for Chubu & 0.030 & 1.187 \\
\hline Dummy for Kinki & -0.110 & -4.567 \\
\hline Dummy for Chugoku & 0.083 & 3.737 \\
\hline Dummy for Shikoku & -0.034 & -1.470 \\
\hline
\end{tabular}

Notes: We use 3 years, 47 prefectures, for 141 observations. The 7 dummy variables are for regions of Japan. Total expenditures and capital costs are normalized in ¥100,000. Standard errors are computed from the heteroscedastic-consistent covariance matrix. 
Table 5: Estimated Own-Price and Cross-Price Elasticities of Each Choice with Respect to Gas Cost $\left(p_{i}\right)$

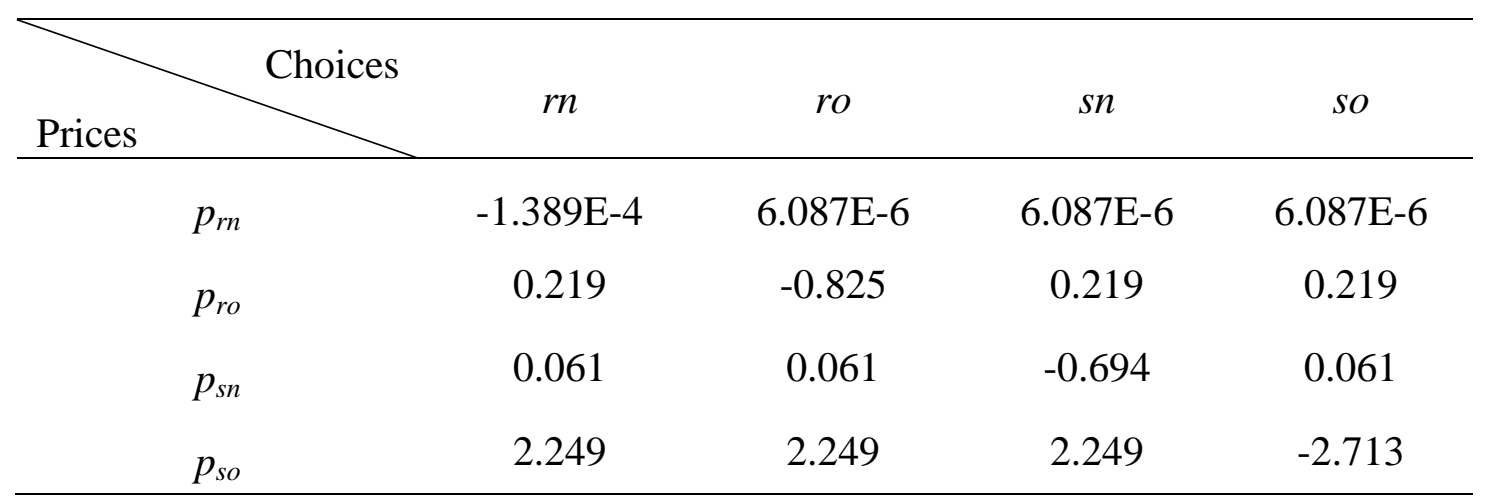

Where $i$ is the row and $j$ is the column, each entry gives the percentage change in probability of choosing car $j$ for a $1 \%$ change in gas cost per kilometer of choice $i$.

Table 6: Estimated Own-Price and Cross-Price Elasticities of Each Choice with Respect to Capital Cost $\left(k_{i}\right)$ and Total Expenditure $(y)$

\begin{tabular}{cccccc}
\hline Choices & rn & ro & sn & so & $\begin{array}{c}0 \\
\text { (no car) }\end{array}$ \\
\hline$k_{r n}$ & -0.0301 & 0.0013 & 0.0013 & 0.0013 & 0.0013 \\
$k_{\text {ro }}$ & $3.54 \mathrm{E}-4$ & -0.0013 & $3.54 \mathrm{E}-4$ & $3.54 \mathrm{E}-4$ & $3.54 \mathrm{E}-4$ \\
$k_{\text {sn }}$ & 0.0011 & 0.0011 & -0.0127 & 0.0011 & 0.0011 \\
$k_{\text {so }}$ & 0.0202 & 0.0202 & 0.0202 & -0.0243 & 0.0202 \\
\hline $\begin{array}{c}\text { Total income, } \\
\text { expenditure }(y)\end{array}$ & -0.717 & -0.876 & -0.766 & 1.038 & -0.909 \\
\hline
\end{tabular}

Where $i$ is the row and $j$ is the column, each entry gives the percentage change in probability of choosing car $j$ for a $1 \%$ change in capital cost of choice $i$. 
Table 7: Short-Run Kilometer Elasticities

\begin{tabular}{lc}
\hline Elasticities of $V K T$ with respect to: & Values \\
\hline gas cost per kilometer of choice $r n\left(e_{p, r n}\right)$ & -11.23 \\
gas cost per kilometer of choice ro $\left(e_{p, r o}\right)$ & -2.378 \\
gas cost per kilometer of choice sn $\left(e_{p, s n}\right)$ & -2.383 \\
gas cost per kilometer of choice so $\left(e_{p, s o}\right)$ & -0.555 \\
total expenditure $\left(e_{y}\right)$ & 0.233 \\
capital cost of choice $r n\left(e_{k, r n}\right)$ & -0.038 \\
capital cost of choice ro $\left(e_{k, r o}\right)$ & -0.012 \\
capital cost of choice $s n\left(e_{k, s n}\right)$ & -0.022 \\
capital cost of choice so $\left(e_{k, s o}\right)$ & -0.005 \\
\hline
\end{tabular}

Note: All the elasticities are evaluated at the mean values of the variables.

Table 8: Comparison of Tax Instruments

\begin{tabular}{llllllllc}
\hline$\Delta \mathbf{p}($ yen $/ \mathbf{k m})$ & $\mathbf{0}$ & $\mathbf{0 . 2 5 4}$ & $\mathbf{0 . 5 0 9}$ & $\mathbf{0 . 7 6 3}$ & $\ldots$ & $\mathbf{4 . 5 7 7}$ & $\mathbf{4 . 8 3 1}$ & $\mathbf{5 . 0 8 5}$ \\
$t_{g}$ (yen/liter) & 0 & 2.690 & 5.380 & 8.070 & $\ldots$ & 48.420 & 51.110 & 53.800 \\
$t_{e}($ yen/gram) & 0 & 0.699 & 1.398 & 2.098 & $\ldots$ & 12.586 & 13.286 & 13.985 \\
$t_{c}($ yen/gram) & 0 & 0.001 & 0.002 & 0.003 & $\ldots$ & 0.021 & 0.022 & 0.023 \\
$t_{d}($ yen/km) & 0 & 0.254 & 0.509 & 0.763 & $\ldots$ & 4.577 & 4.831 & 5.085 \\
\hline
\end{tabular}

Note: In each column, rates for the different tax instruments all induce the same change in price per kilometer as given in the first row in bold. The average price of gasoline in our data is $101.96 ¥ /$ liter. 
Figure 1: Effects of Four Policies on Vehicle-Kilometers Traveled (VKT)

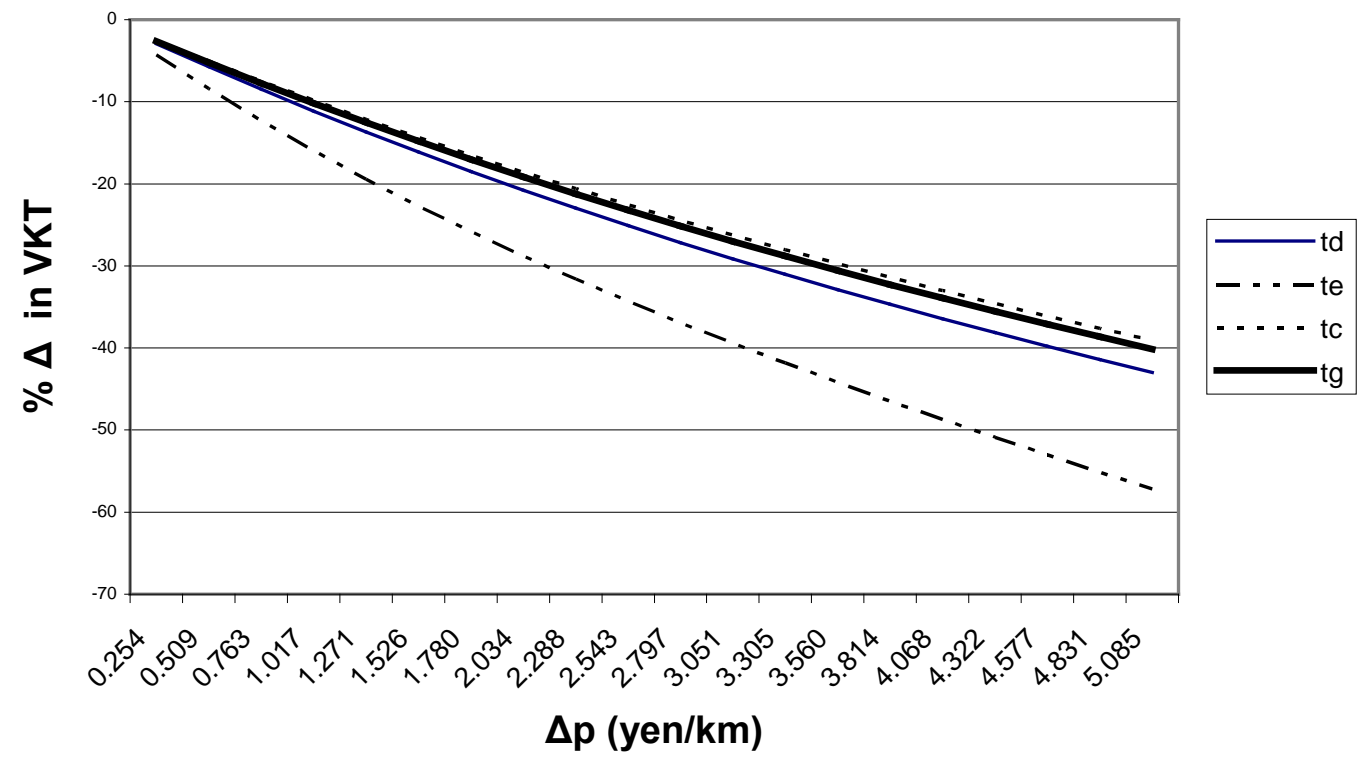

Figure 2: Effects of Four Policies on Local Emissions (LE)

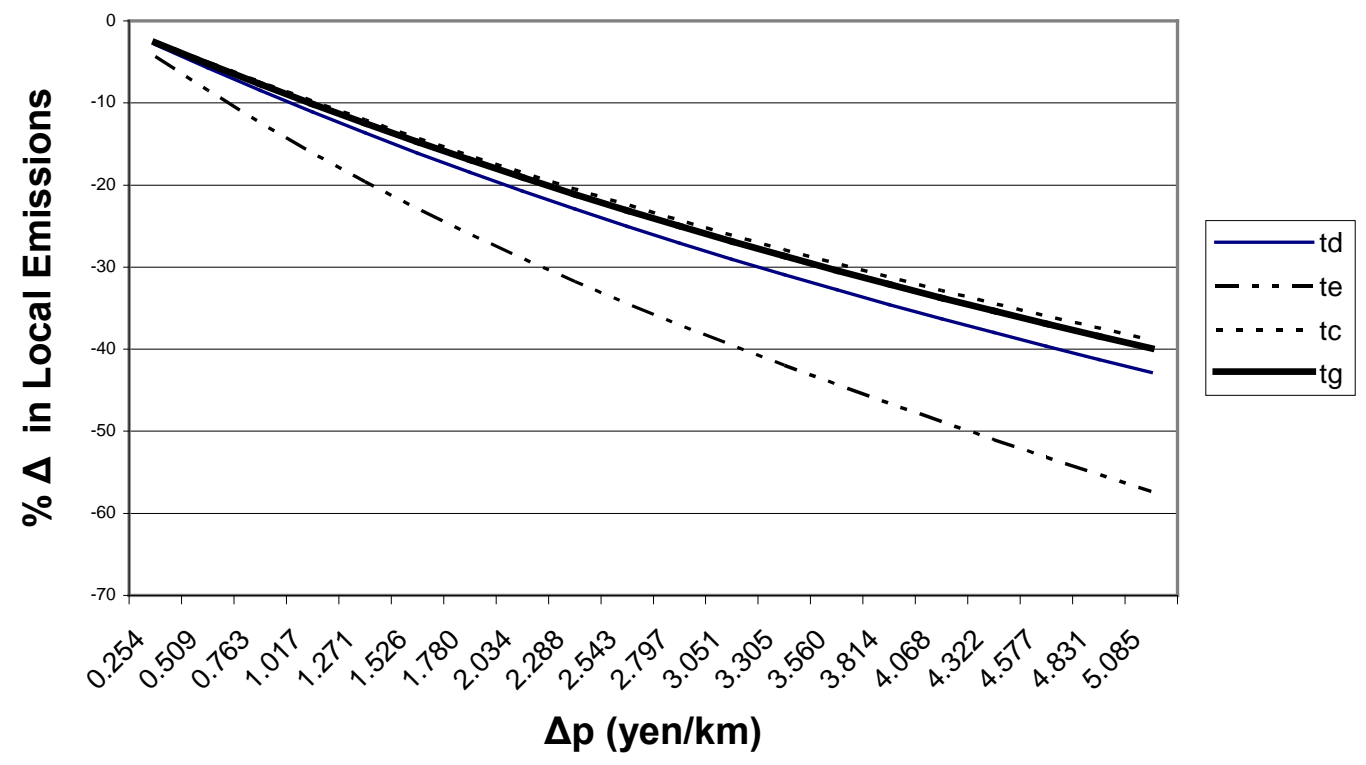


Figure 3: Effects of Four Policies on Carbon Emissions

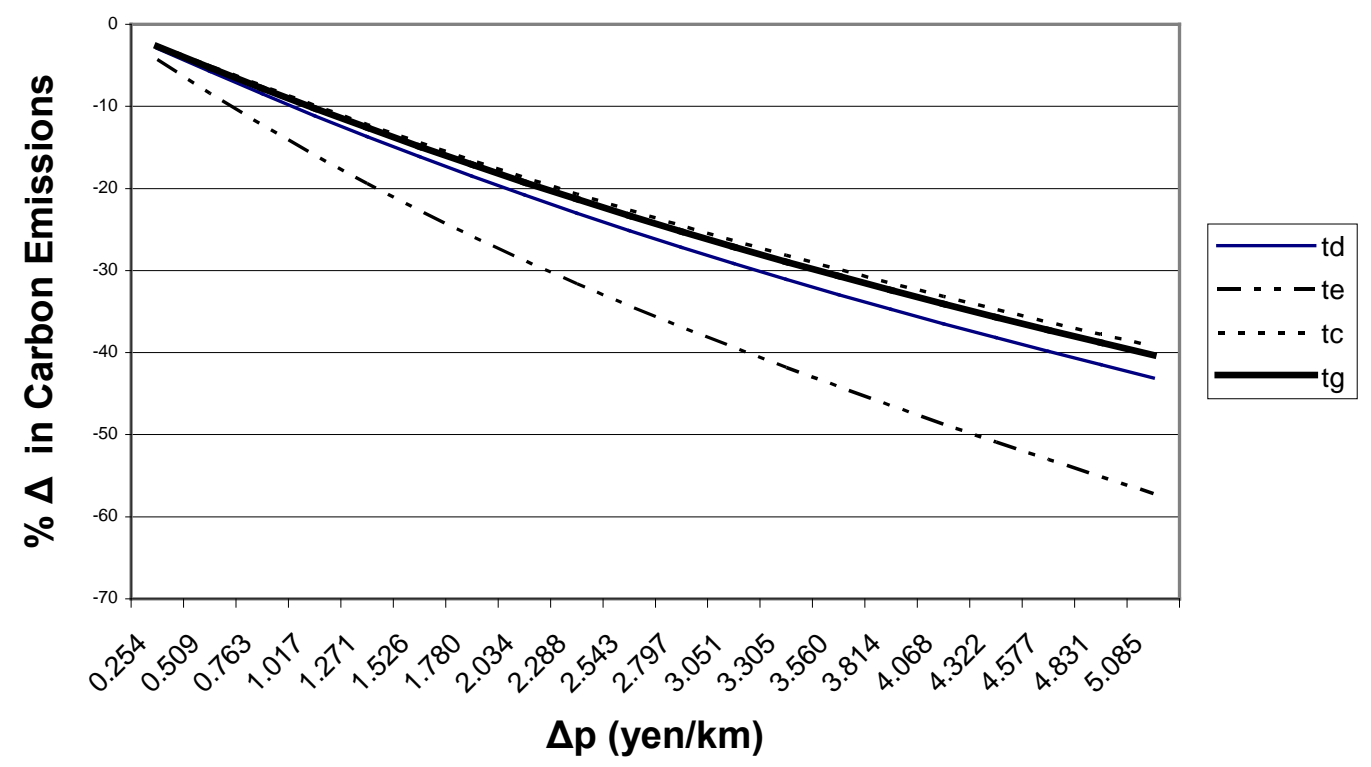

Figure 4: Effects of Emission Tax on Market Shares of Cars

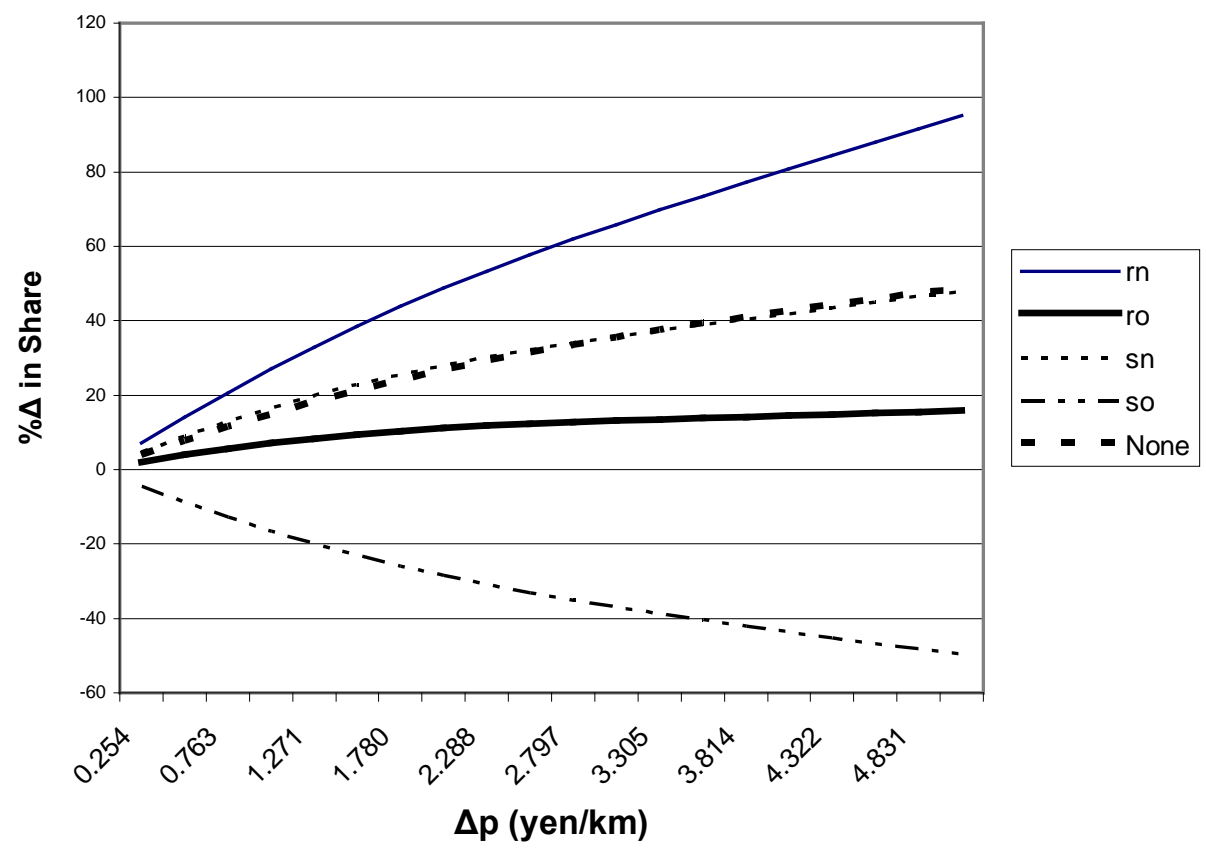


Figure 5: Effects of Carbon Tax on Market Shares of Cars

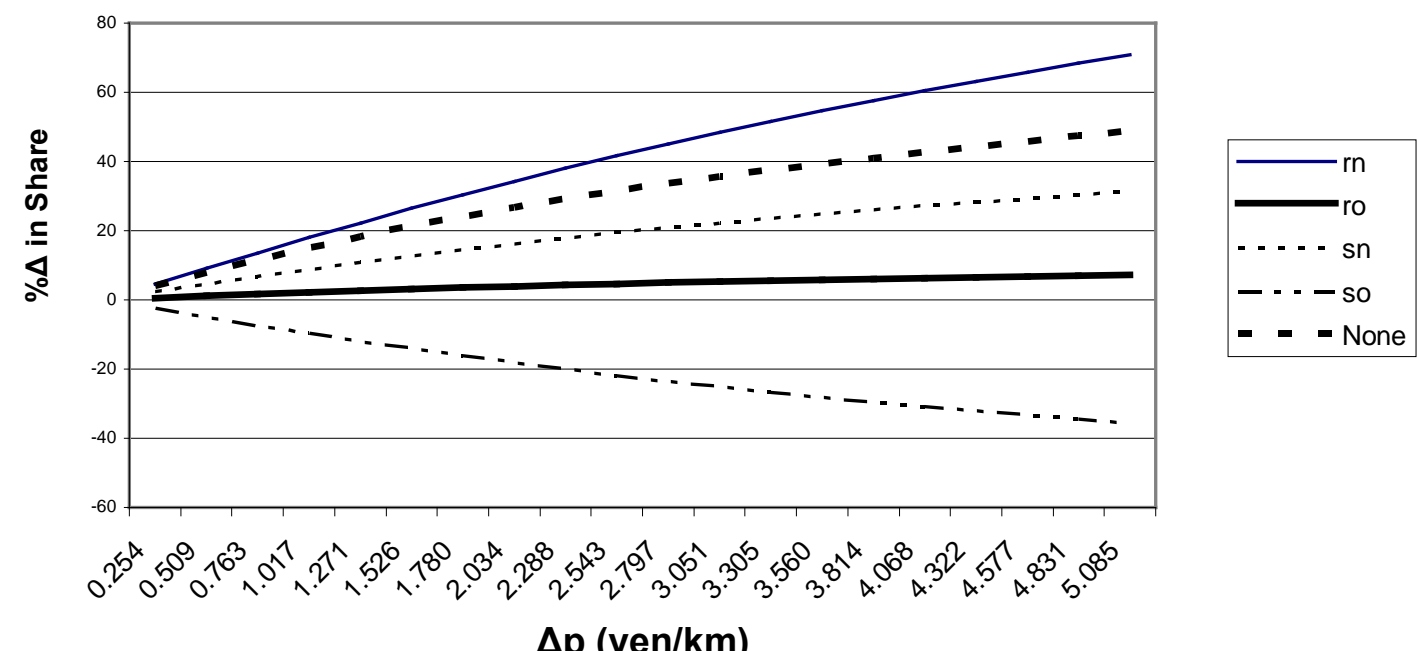

Figure 6: Effects of Gasoline Tax on Market Shares of Cars

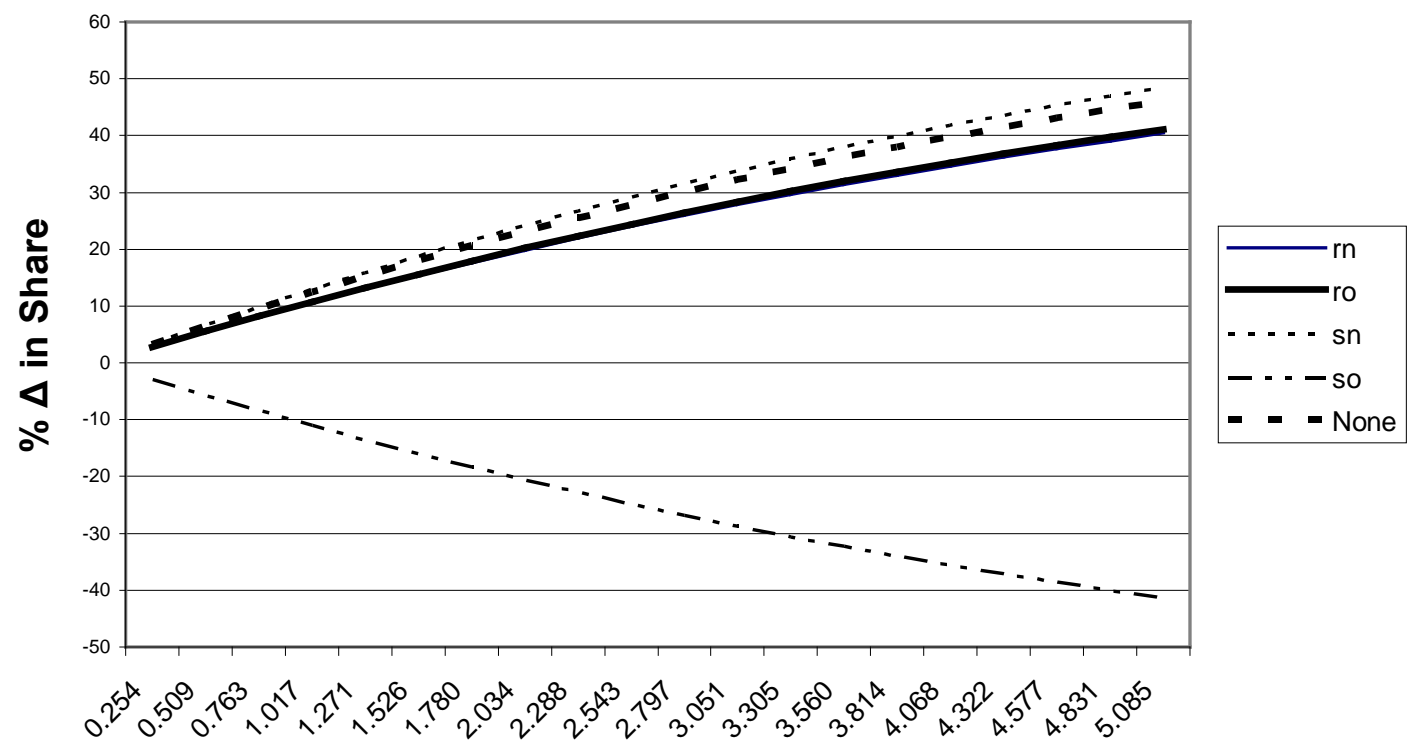

$\Delta p(y e n / k m)$ 
Figure 7: Effects of Distance Tax on Market Shares of Cars

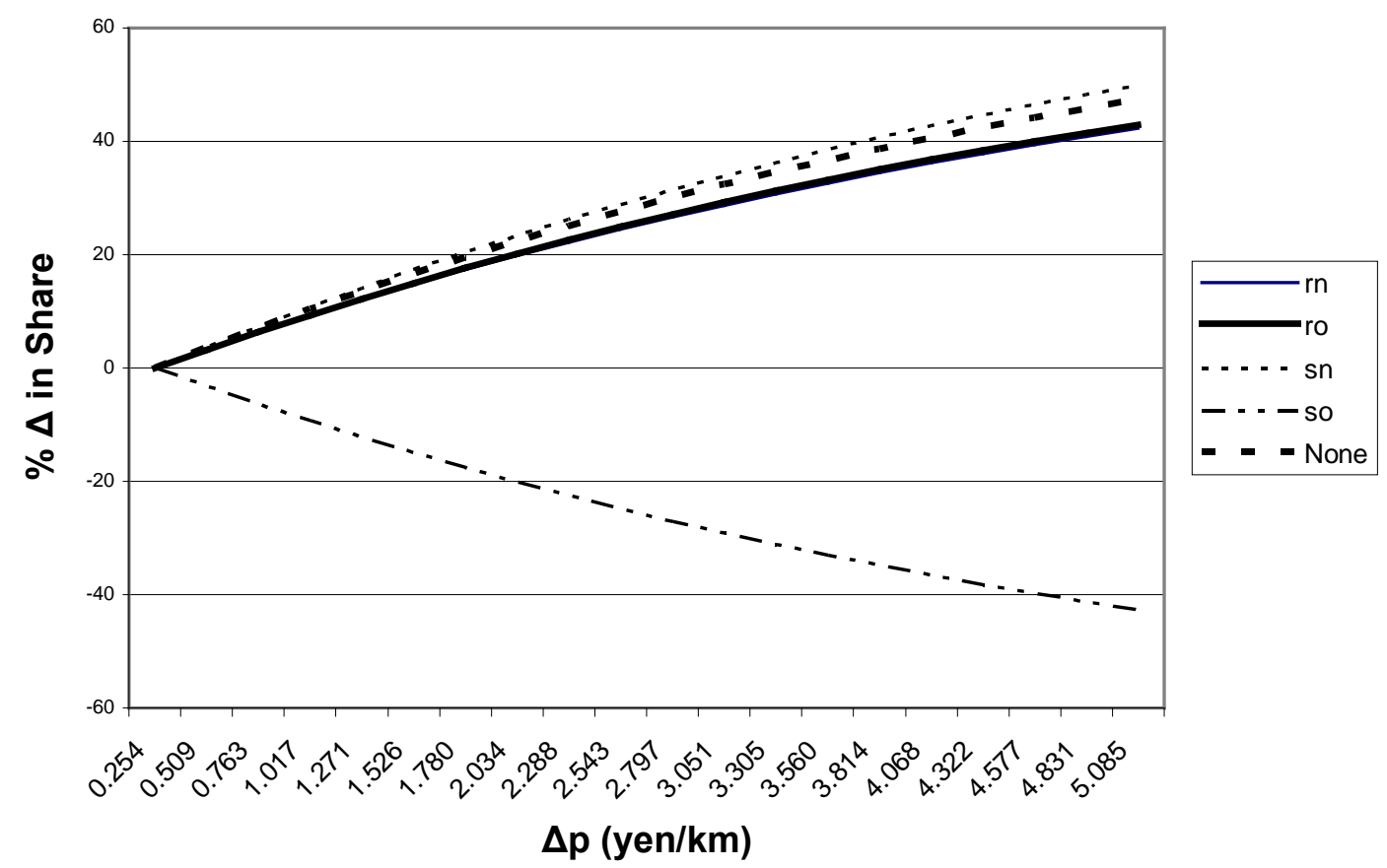

Figure 8: Effects of Size Tax on VKT, Carbon, and Local Emissions (LE)

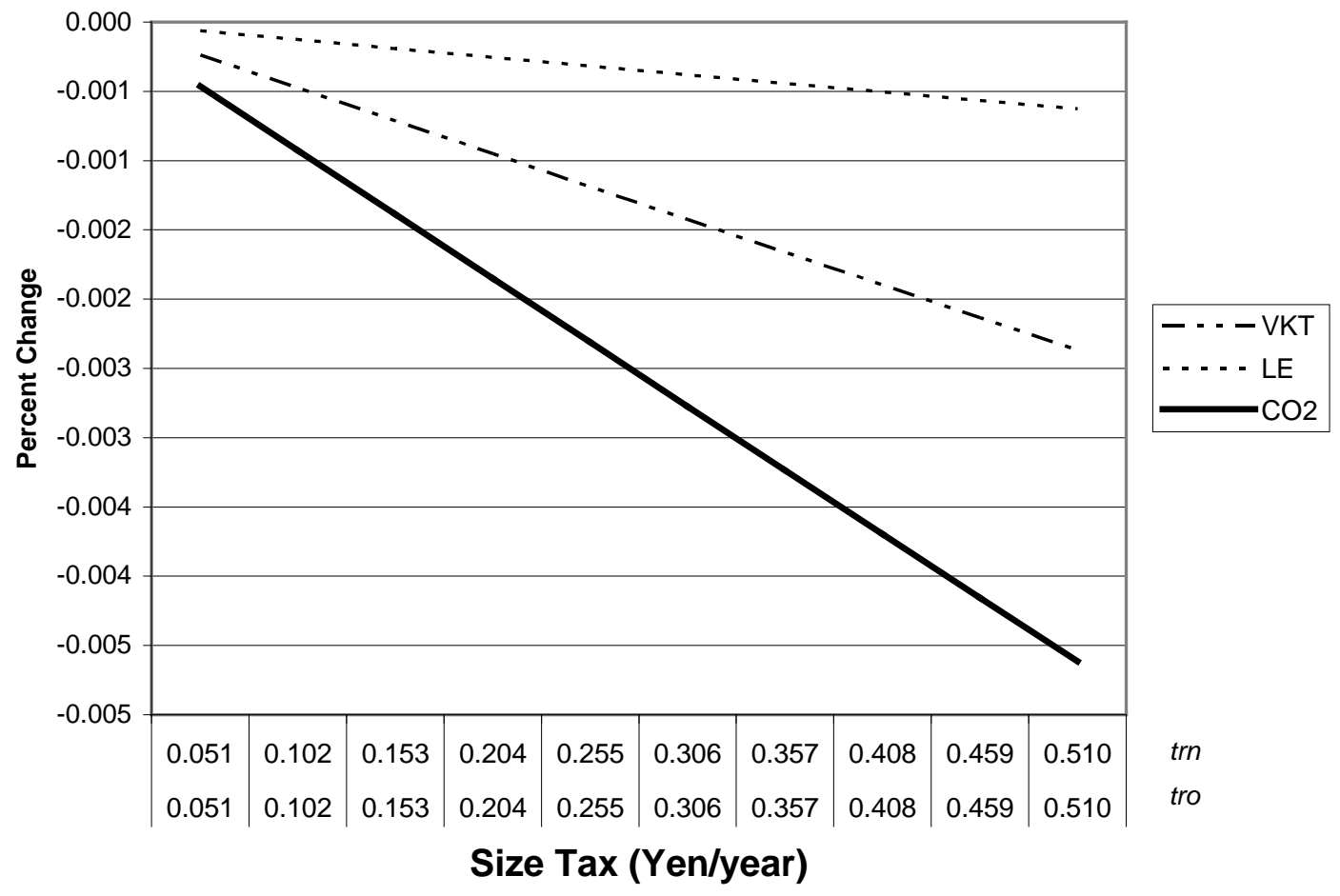


Figure 9(a): Effects of an EPK-Proportional Tax

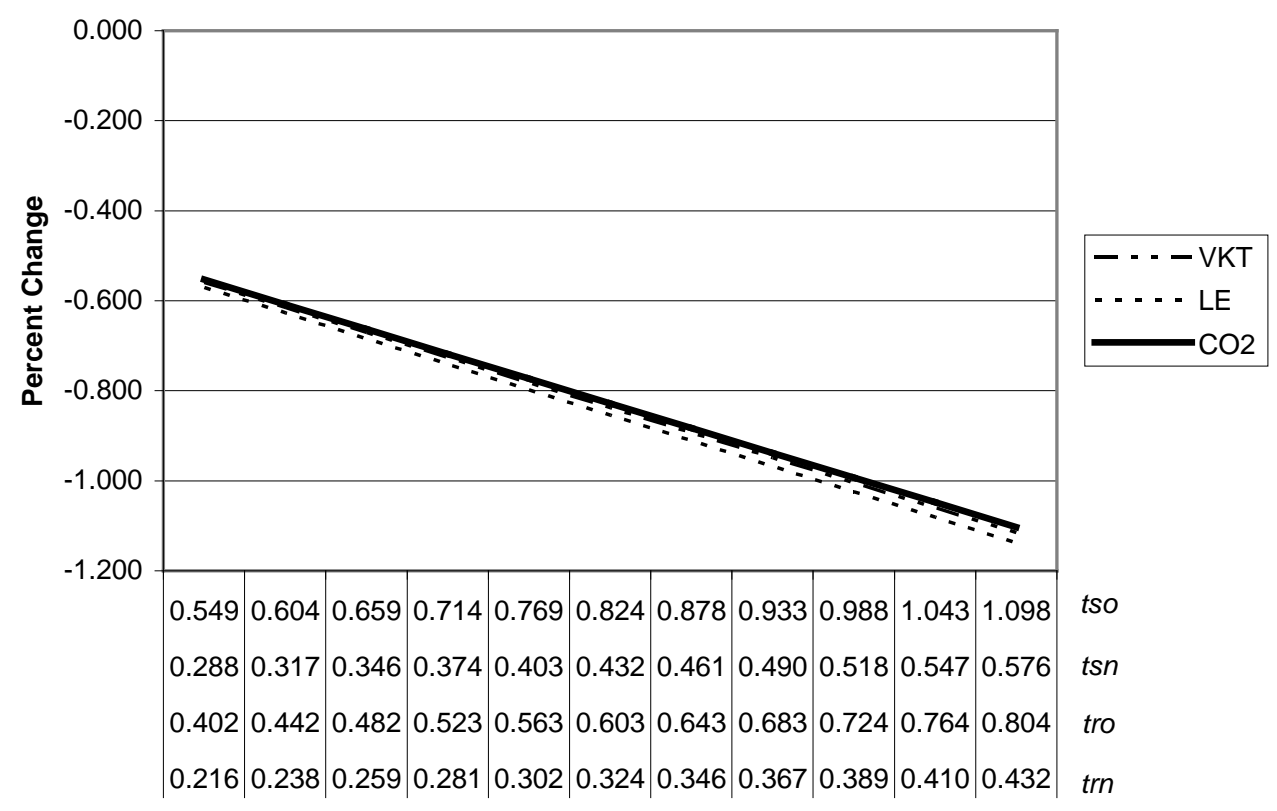

EPK-Proportional Tax (Yen Per Year)

Figure 9(b): Effects of an EPK Tax on Market Shares of Cars

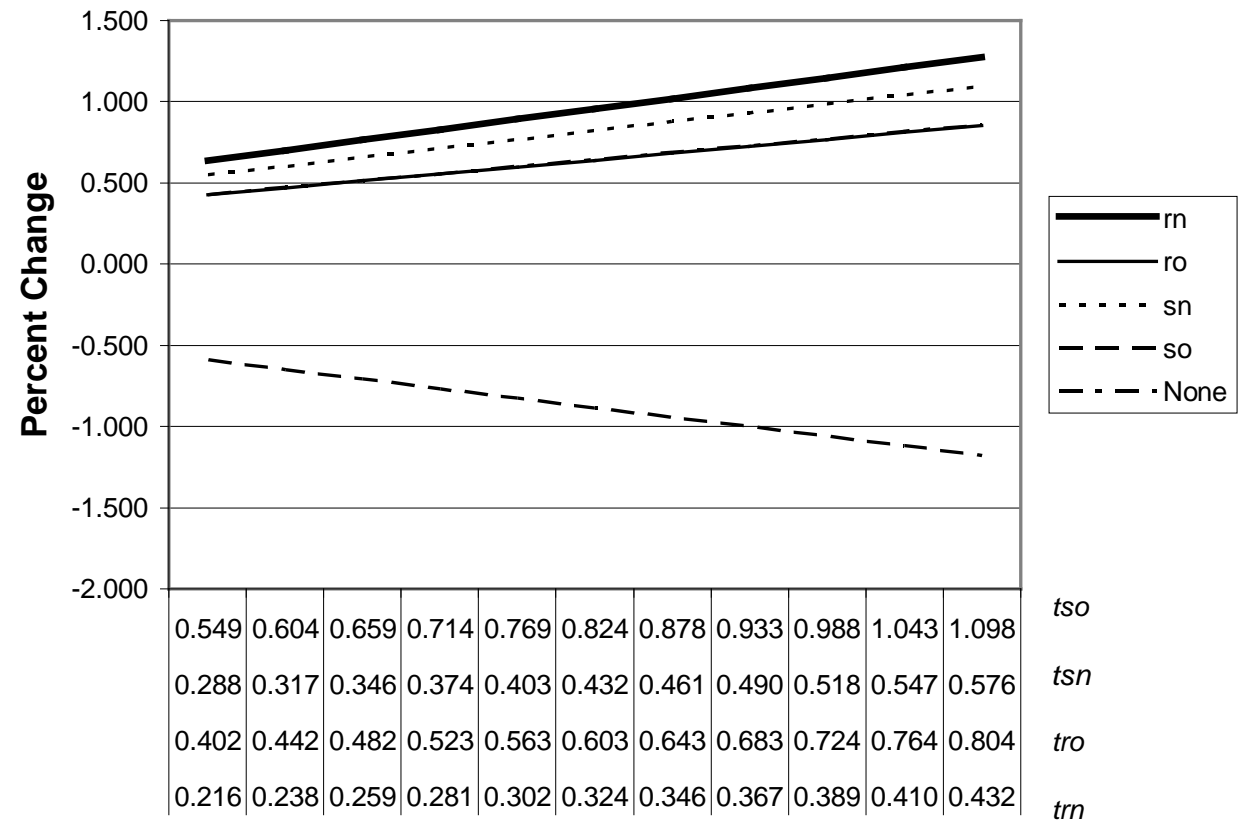

EPK-Proportional Tax (Yen Per Year) 
Figure 10 (a): Effects of a Tax on Old Cars

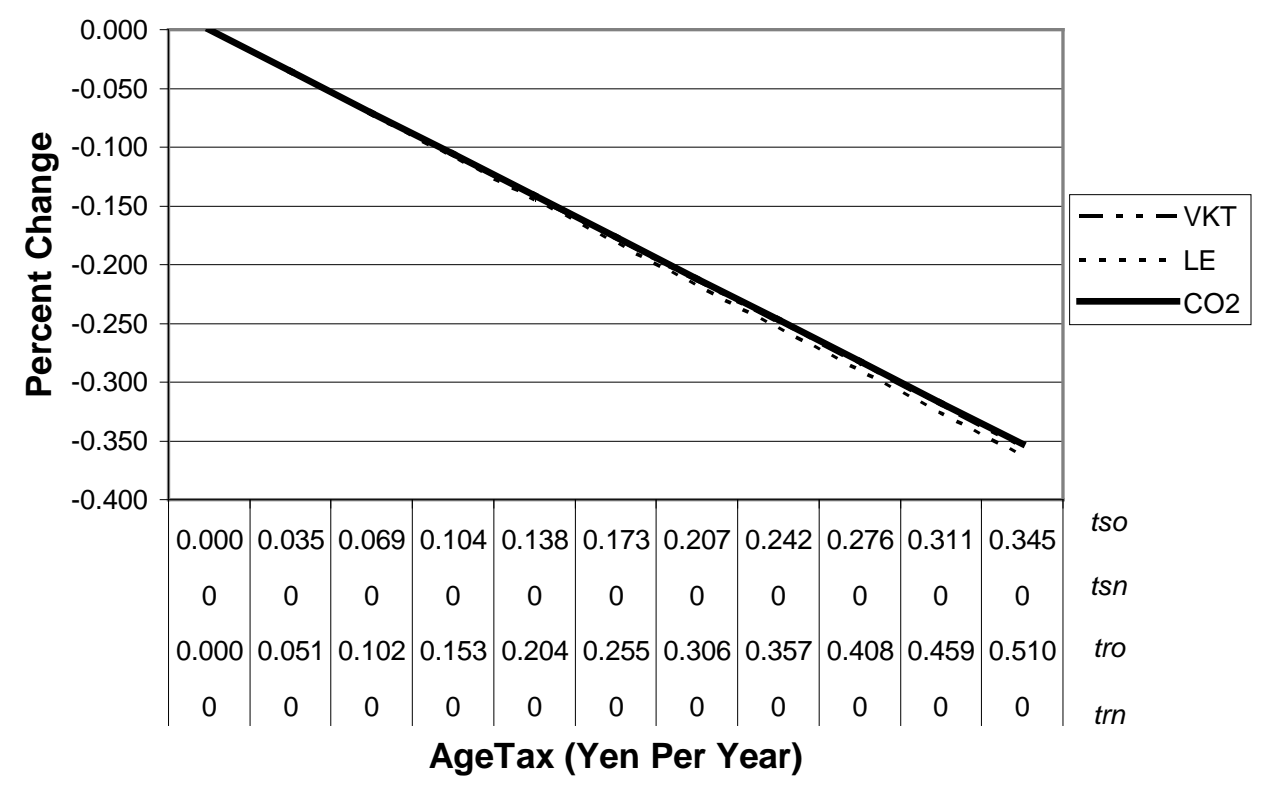

Figure 10 (b): Effects of a Tax on Old Cars on Market Shares of Cars

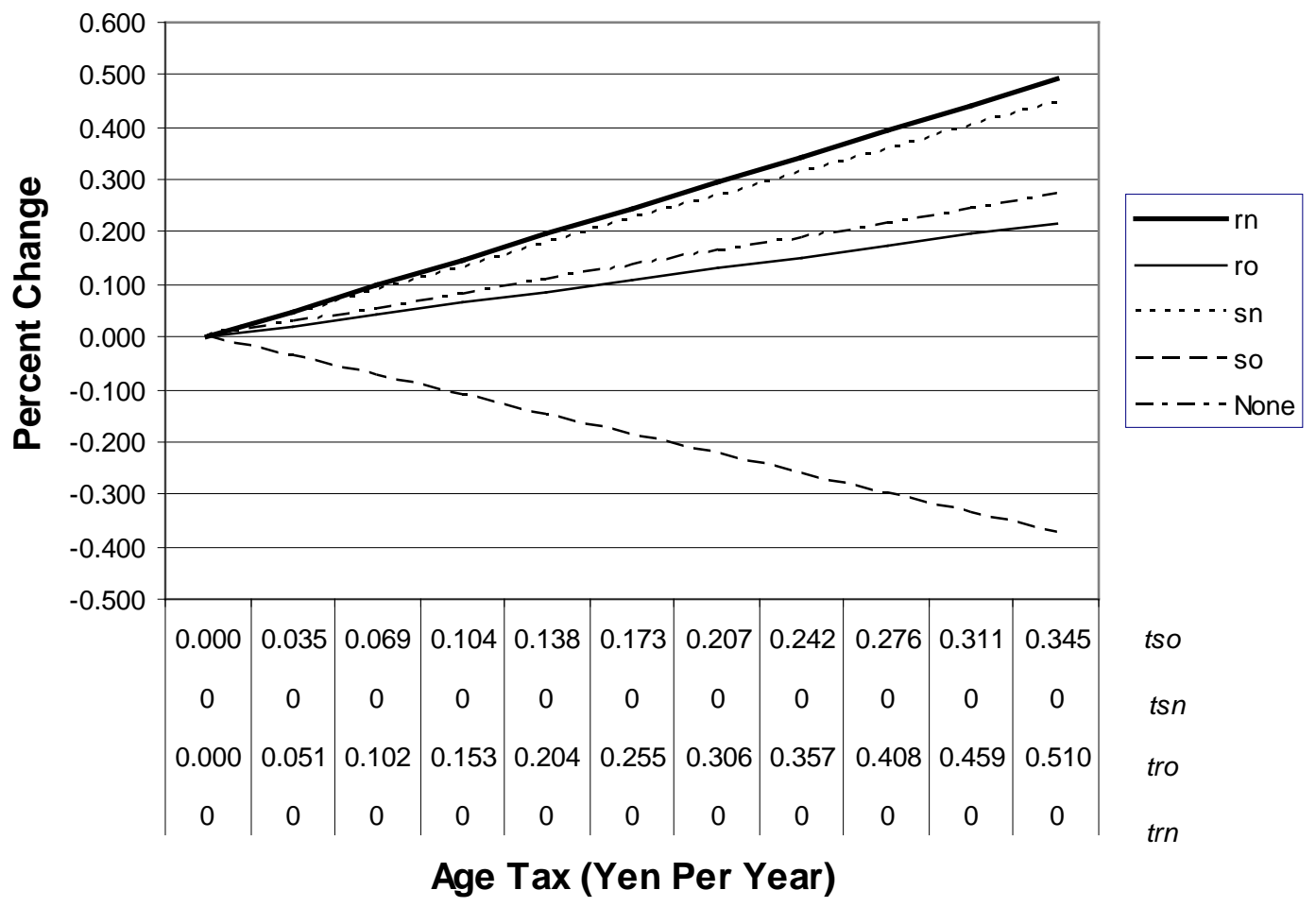


Figure 11: Marginal Cost of Abatement (MCA) for Local Emissions

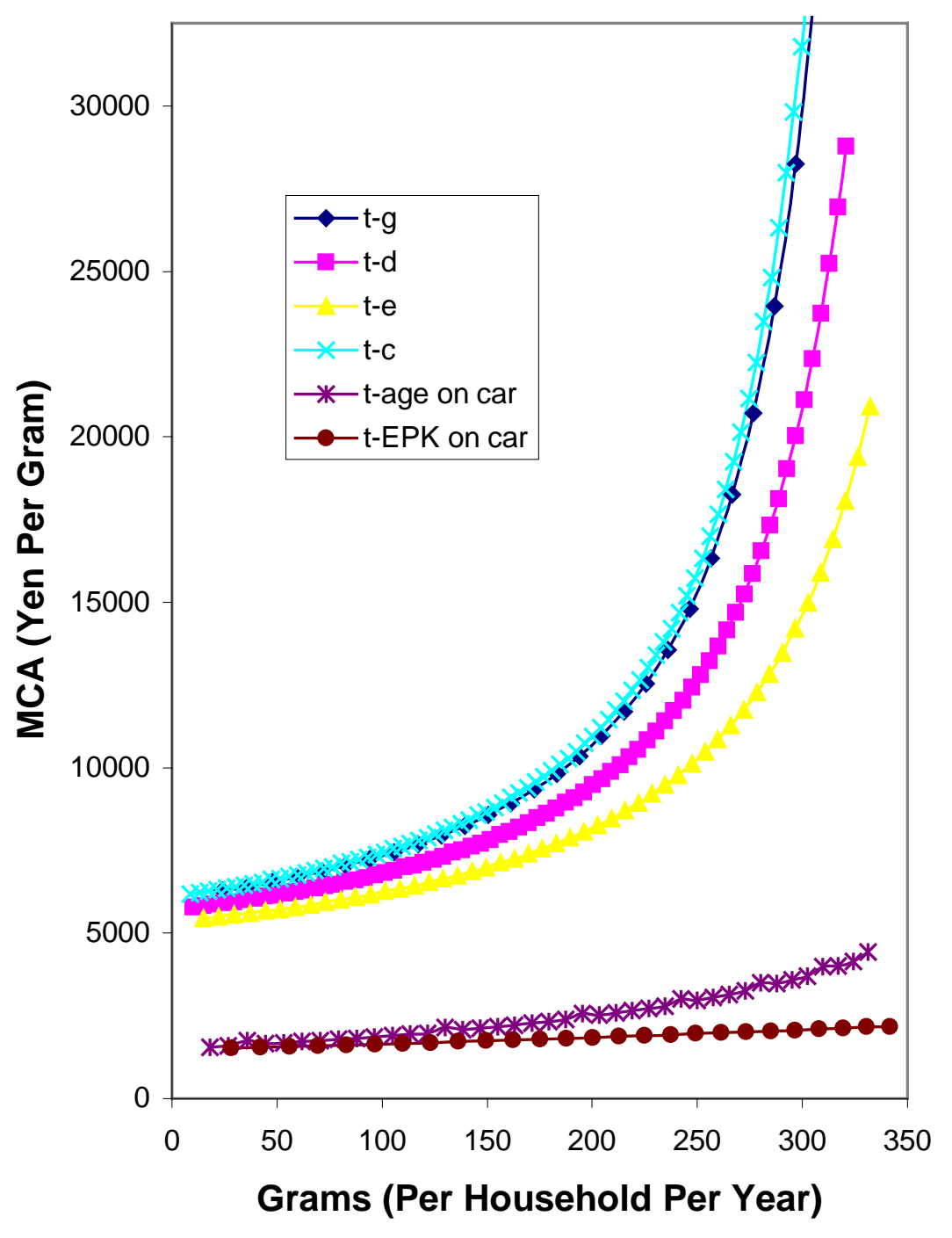

